\title{
La risa en Francisco Suárez. El paso de la Edad Media al Barroco
}

\section{The laugh in Francisco Suárez. The passage from the Middle Ages to the Baroque}

\author{
Manuel Lázaro PULIDo \\ Universidade do Porto
}

Recibido: 17-05-2011

Aceptado: 04-11-2011

\section{Resumen}

El estudio muestra la relación entre la tradición medieval presente en la segunda escolástica y las consecuencias en el Barroco del humanismo renancentista, a partir de la referencia que hace Suárez a la risa en el Comentario al De anima. Aparece un desarrollo de la temática clásica y medieval sobre la risa, donde se tiene en cuenta la esfera intelectual del Humanismo científico y se señalan algunas temáticas que se tendrán presente en el Barroco moderno.

Palabras clave: risa, Suárez, 'De anima', humanismo, humanismo científico, Segunda Escolástica, filosofía del siglo XVI, pensamiento medieval.

\begin{abstract}
This paper shows the relationship between the medieval tradition, presents at the Second Scholastics and the consequences the Renaissance Humanism in the Baroque, from the Suarez's reference of the laugh in Comment to De anima. In this topic appears a development of the classic and medieval laugh subject, and also the Humanism scientific context presents in the modern Baroque.
\end{abstract}

Keywords: Laugh, Suárez, 'De anima", Humanism, Scientific Humanism, Second Scholastic, 16th Century Philosophy, Medieval thought. 
En el siglo XX Henri Bergson sacó a la luz el tema de la risa trayéndolo a la esfera de la especulación filosófica en su libro Le rire. Essai sur la signification du comique ${ }^{1}$. El menor pero muy conocido estudio del filósofo francés señalaba la función que podemos llamar "positiva" de la risa y del humor de donde nace. La lectura que propicia la "humanidad" de la risa, su especificidad en el hombre ("Voici le premier point sur lequel nous appellerons l'attention. Il n'y a pas de comique en dehors de ce qui est proprement humain"2) y en ello su lectura "social", asentándose en la tradición cómica europea, especialmente en la esfera francesa, en un sentido intelectualista. En contraposición, como señala Reis ${ }^{3}$, Ch. Lalo reinterpreta desde una lectura estética los ejemplos del filósofo francés para criticar estas características (especialmente, la insensibilidad) en aras a una mirada menos intelectualista del acto del reír y, en ello, sin negar la óptica al otro, personalizando dicho acto ${ }^{4}$. La risa abandonaba, así, la anécdota (al menos desde el punto de vista popular), sin llegar a ser más de lo que era en la reflexión antropológica, toda vez como acontecía en los tiempos precedentes. La risa no siendo un elemento central de la preocupación filosófica, pero inserta en la actividad humana, ha supuesto un elemento de reflexión que no ha abandonado la esfera filosófica. Y este elemento antropológico y de ejercicio filosófico ayuda a comprender, estudiado en el tiempo, elementos filosóficos de mayor calado y trascendencia, como puso de relieve la obra de Bergson. Si bien no podemos olvidar que "la risa ha sido siempre un objeto de estudio tan escurridizo como capaz de suscitar vértigo y obsesión"5.

La risa aparece, pues, sistemáticamente en diversos puntos de la historia del pensamiento, estudiado o mencionado en los lugares filosóficos, poco a poco explicado en los tratados médicos, expresado en la literatura y retratado en el arte. La risa no escapa a los autores significativos de sus épocas aunque aflore de forma más o menos marginal. La variación de la tematización de la risa nos puede servir de coartada, al menos en nuestro caso, para comprender el movimiento y dinamismo de la historia de la filosofía en la construcción de las bases del pensamiento moderno. Más aún, la utilización de una forma determinada del elemento de la risa puede ayudar a vislumbrar elementos básicos de la historia de la filosofía.

\footnotetext{
${ }^{1}$ H. Bergson, Le rire. Essai sur la signification du comique, Éditions Alcan, Paris 1924 (publicación original en tres artículos en Revue de Paris, en 1900: 1er février 1900, pp. 512-544, 15 février 1900, pp. $759-790$ et 1 er mars 1900 , pp. 146-179. $1^{\text {a }}$ ed. 1900).

2 Ibid., p. 3

3 Cf. J.E. Reis, "O Riso estético segundo Bergson e Lalo", Revista Filosófica de Coimbra, 2 (1993) 313-368.

${ }^{4}$ Cf. Ch. Lalo, Esthétique du rire, Flammarion, Paris 1949, p. 241.

5 A. Castañón, "Sobre la Risa. Bárbara Jacobs, Nin reír / La risa a lo largo de la historia, la ciencia, el arte, mi vida y la literatura. México, Taller Ditoria/Consejo Nacional para la Cultura y las Artes, 2009, 132 pp.”, Letras libres, 139 (Julio/2010) 91-92.
} 
En este sentido, la risa, como lugar que emerge de forma casi circunstancial en Suárez en su comentario al De anima, es la escusa que utilizamos para poder ver el contexto filosófico de la Segunda Escolástica y su papel en una mejor comprensión del salto que se realiza de una mentalidad gótica a una mentalidad barroca, de la Edad Media a la Edad Moderna, una continuidad que no se realiza, creemos, a saltos. El topos de la risa ya lo hemos utilizado para poner en cuestión la importancia de la Segunda Escolástica tardía del siglo XVI como lugar de expresión del Humanismo en su utilización en el Cursus Conimbricensis ${ }^{6}$, rescatamos este contexto y ampliamos la óptica del Humanismo hacia el Barroco. Y para ello utilizamos la reflexión suareciana como expresión de la inevitable evolución del pensar humano y su continuidad aún en el disenso de las conclusiones y las perspectivas.

\section{La risa, expresión física de las pasiones humanas}

Article 124. Du Ris. Le Ris consiste en ce que le sang qui vient de la cavité droite du cœur par la veine arterieuse, enflant les poumons subitement et a diverses reprises, fait que l'air qu'ils contient est contraint d'en sortir avec impétuosité par le sifflet, où il forme une voix inarticulée et éclatante ; et tant les poumons en s'enflant que cet air en sortant poussent tous les muscles du diaphragme, de la poitrine et de la gorge : au moyen de quoi ils font mouvoir ceux du visage qui ont quelque connexion avec eux. Et ce n'est cette action du visage, avec cette voix inarticulée et éclatante, qu'on nomme le Ris?.

Con el artículo 124 inaugura Descartes una aproximación a la risa a la que le siguen los artículos 125 y 126, donde el filósofo francés introduce en la explicación física de la risa su fondo pasional y psicológico, acercándolo a la alegría moderada (125. Pourquoi il n'accompagne point les plus grandes joies) que continúa en el artículo 126: la sorpresa de la admiración (nacida de la alegría o del odio) y la mezcla de algún licor.

En este punto sobre la risa, los elementos que aparecen reflejan el estado de cosas del tiempo de Descartes y de su propio genio. Por una parte, vemos la explicación fisiológica de la risa. Por otra parte, podemos observar su etiología psicológica. Por fin, dentro de la explicación de las pasiones, aparece mencionado como causa psicológica principal, más que la alegría o el odio en sí, la referencia al hecho de la admiración; uno de los elementos centrales en su análisis de las pasiones. Alegría, odio, deseo y amor son de gran importancia, pero la admiración es la

${ }^{6}$ Cf. M. Lázaro, "Presencia humanista en el Cursus Conimbricensis: Disputatio de risu (De anima III, q. XIII a. VI)", Revista Filosófica de Coimbra, 20 (2011) 413-438.

7 R. Descartes, Des passions de l'âme, vol. XI, (Euvres de Descartes, Ch. Adam - P Tannery (eds.) 12 vols., J. Vrin - CNRS, Paris 1964-1976, p. 419 = AT, XI, 124, p. 419). 
pasión que se relaciona de forma especial con el cerebro, imprime una etiología antropológico-epistemológica, conditio sine qua non para imprimir conocimiento.

Descartes difiere de la concepción medieval, especialmente la tomista, de la clasificación de las pasiones. Donde el teólogo medieval incluye una clasificación en torno a una concepción de división del alma (a partir de los apetitos del alma ${ }^{8}$ ), Descartes "prefiere fijarse en las fuentes primarias de las pasiones como hilo conductor en la enumeración y ordenamiento de las pasiones"9. Si Tomás de Aquino distingue las pasiones a partir de las facultades sensitivas (concupiscible e irascible) donde las pasiones responden a un bien o un mal origen de la reacción que es una pasión; Descartes advierte que la pasión es un correlato del acto de evaluación. De modo que el acto valorativo se apoya en la representación del bien (aceptación) o el mal (reprobación), en coherencia con el subjetivismo de las Méditations, y las pasiones responden al sujeto como principio epistemológico y alejado del hecho de la realidad en sí, como se definía la pasión a partir del influjo del pensamiento tomista en el siglo XVII francés ${ }^{10}$. Formulaciones tradicionales paralelas que aparecen en autores como el dominico Nicolas Coeffeteau (1574-1623) [“passion, n’est autre chose qu'un mouvement de l'appétit sensitif, causé de l'appréhension ou de l'imagination du bien ou de mal, qui est suivi d'un changement qui arrive au corps, contre les lois de la nature"11], Jean-Pierre Camus (1584-1652) ["un mouvement de l'âme que se fait en l'appétit sensitif pour la suite d'un bien ou la fuite d'un mal, vrai ou apparent"12] o Marin Cureau de La Chambre (1594-1669) ["Je suppose donc que les passions sont des mouvements de l'Appétit, par lesquels l'Ame tache de s'approcher du bien et de s'éloigner du mal"13].

La actitud de Descartes no implica tanto una posición primaria contra el escolasticismo, cuanto una lectura diferente al aristotelicismo como sistema omnicomprensivo. Como veremos, ya en los propios comentarios y la pedagogía eclesiástica, el aristotelicismo aunque aceptado en esa época, era reinterpretado de modos diversos, de forma más o menos sutil. Como recuerda Roger Ariew, la pedagogía jesuita conocida por Descartes en el Collège de la Flèche no le es esquiva e incluso es ponderada por él; esta mostraba, aún después de Malebranche, a inicios del

\footnotetext{
8 Cf. Article 68.

9 A. Izquierdo, "Prólogo", en R. Descartes, Las pasiones del alma, EDAF, Madrid 2006, p. 38.

10 Cf. A. Levi, French moralists: the theory of the passions, 1585 to 1649, Clarendon Press, Oxford 1964.

11 F.N. Coeffeteau, Tableau des passions humaines, de leurs causes et de leurs effets, S. Cramoisy, Paris 1620, p. 2.

12 Jean-Pierre Camus, Traité des passions de l'âme, en Diversités, t. IX, p. 70, cita tomada de P. d'Arcy, "Introduction", en R. Descartes, Les passions de l'âme, intr., not., bibli. P. d'Arcy., Flammarion, Paris 1996, p. 16.

13 Marin Cureau de La Chambre, "Advis necessarie au Lecteur", en Les charactères des passions. Volume 1, Jacques D’Allin, Paris 1662, n.p. (1ª impresión 1640).
} 
siglo XVIII, señales de libertad en la elección del profesorado como lo evidencia la enseñanza del jesuita cartesiano Père André14.

En este movimiento intelectual hacia el sujeto como motor de las pasiones juega un papel importante la admiración. Es la admiración, la primera de las pasiones primitivas, la que hace imposible la validez de las definiciones tradicionales que hemos visto y que se sustentan en la interpretación tomista, donde la pasión se orienta hacia el bien y el mal, a través de la fuerza o el impulso amoroso. Laurence Renault ha evidenciado la importancia de la admiración en la dinámica de las pasiones cartesianas, el modo como la novedad producida ante una cosa provoca que pasemos de un estado de ignorancia a otro de conocimiento. Este movimiento constituye un paso epistemológico, pero, sobre todo, el reconocimiento estimativo de una realidad que nos provoca admiración ${ }^{15}$. El autor examina el análisis de la pasión que provoca la generosidad, como forma de estima de uno mismo (art. 160). La generosidad, o sea la forma legítima de estima de uno (el orgullo sería la ilegítima) provoca admiración en la medida que viene marcada no solo de la realidad en sí del soberano bien, sino en cuanto que el soberano bien es una voluntad de hacer bien; y la alegría que produce hacerlo ${ }^{16}$, un conocimiento que provoca admiración, porque Dios provoca en el hombre la admiración. El libre arbitrio y Dios son las dos realidades que causan admiración, y le convierten en una forma de criterio de demarcación de la posesión y jerarquización de los bienes: "Chez Descartes, c'est par un usage réglé de l'admiration que s'opère cette discrimination entre le souverain bien et les autres biens, c'est-à-dire entre le droit usage du libre arbitre et les biens de la fortune" 17 .

Esta actitud cartesiana respecto a las pasiones a partir del elemento de la admiración refleja una distancia con el precedente medieval de Tomás de Aquino, según L. Renault, toda vez que la admiración en el Aquinate se muestra como un punto de apoyo para la determinación de la naturaleza de la felicidad, es decir, la contemplación divina ${ }^{18}$. La reinterpretación cartesiana de la noción aristotélico-tomista de la admiración -afirma Renault- provoca que las pasiones ocupen un lugar central en la virtud y la felicidad humanas ya que estas implican un principio de movimiento en la perfección moral, en el hecho de que llevan al conocimiento y posesión del soberano bien. Este es un hecho que lo separa del estoicismo y del peripatetismo,

14 R. Ariew, "Descartes and scholasticism: the intellectual background to Descartes' thought", en J. Cottingham, The Cambridge Companion to Descartes, Cambridge University Press, Cambridge 1992, p. 80. Recuerda las palabras del propio Descartes citadas en Inglés: "there in no place on earth where philoso-phy is better taught than at La Flèche" (Ibid., p. 59, cita tomada de AT, II, p. 378).

15 L. Renault, "Nature humaine et passions selon Thomas d'Aquin et Descartes", en B. Bernier, P.-F. Moreau - L. Renault, Les passions antiques et médiévales, PUF, Paris 2003, pp. 247-267.

16 AT, V, 82, pp. 30-31.

17 Ibid., p. 260.

18 Ibid., p. 262. Cita Thomas de Aquino, Ia-IIae, q.3, a.8 resp. 
un acontecimiento conceptual en principio no referenciado antes, un salto de la Edad Media al Barroco. Y esa admiración aparece, como hemos visto en el texto cartesiano, en la risa, siendo su causa, un hecho que en principio parece lógico en Descartes y novedoso, pero que, como veremos, ya aparece en Suárez. De forma diferente, pero aparece; quizás para mostrar, una vez más, que la novedad de un pensamiento y su grandeza no implica nunca un salto desde el vacío, sino el imparable ejercicio del diálogo socrático.

\section{La risa en la Escolástica medieval}

La época medieval, a pesar de la imagen de seriedad teológica que nos pueda venir a la memoria, no es ajena al tema del humor, ni tampoco al de la risa. De hecho, la Edad Media realizó una teoría general de la risa en la que se manifestaban elementos variados referidos a sus aspectos antropológicos, psicológicos, humorales y morales, elaborando una tratado orgánico estructurado doctrinalmente y expresado religiosamente ${ }^{19}$. Encontramos respecto al estudio o mención de la risa una mirada que podemos llamar positiva o tolerable y otra negativa o rechazable; visiones que no siempre van estrictamente ligadas a una literatura profana para la primera y teológica para la segunda, si bien es cierto que esta correlación existe con los matices que son necesarios apuntar y señalar. No obstante, la risa en un desarrollo intelectual y teológico muestra su sentido positivo relacionado a las propiedades humanas (la risa es un elemento característico del hombre) y en contraprestación advirtiendo siempre, desde una óptica moral, la posibilidad de un desenfreno pasional irreverente que puede ser muestra de una actitud de alejamiento de Dios, o sea, de pecado.

Una muestra del análisis realizado sobre el fenómeno de la risa nos lo proporcionan estudios medievales en los que se hace una descripción de la misma, es el caso de Giuglio Peraldo O.P. traído a la memoria medieval sobre la risa por Silvia Magnavaca. La autora recuerda la descripción del fraile del siglo XIII, donde aparecen los diferentes elementos que subyacen al fenómeno de la risa, sean retóricos, médico-psicológicos o morales. Así el religioso dominicano Peraldo señala que la risa es, efectivamente, una característica humana que le es propia (risu naturalis), que puede ser objeto moralmente aconsejable (risu commendabilis) o, al contrario,

19 F. Moretti, La ragione del sorriso e del riso nel Medioevo, Edipuglia, Santo Spirito (Bari) 2001, p. 12. Otros trabajos a tener en cuenta son: J. Horowitz y S. Menache, L'humour en chaire. Le rire dans l'Église médiévale, Labor et Fides, Paris 1994; F. Moretti, Il riso: atti delle I Giornate internazionali interdisciplinari di studio sul Medioevo: "Homo risibilis», capacità di ridere e pratica del riso nelle civiltà medievali (Siena, 2-4 ottobre 2002), Edizioni dell'Orso, Alessandria 2005; C. Mazzucco (ed.), Riso e comicità nel cristianesimo antico. Atti del Convegno di Torino, 14-16 febbraio 2005, e altri studi, Ed. dell'orso, Alessandria 2007. 
utilizado de forma perversa desde el punto de vista moral (risu vituperabilis). El aspecto amable (recomendable) de la risa puede indicar un tipo que señala la amabilidad o afabilidad (risu affabilis) y que tiene un carácter de sociabilidad en sus aspectos relacionales, o como estrategia de sociabilidad, de inteligencia social (risu prudentiae). Este aspecto positivo se relaciona, por lo tanto, con el aspecto natural del hombre en cuanto ser que vive en sí y con los otros. El aspecto, que podemos llamar negativo, expresa una desviación que afecta la moral y el propio desarrollo normalizado de la naturaleza humana, al tiempo que pervierte las relaciones sociales que se establecen desde ahí. De esta forma cabe entender la risa del envidioso (risu invidiae) que tiene como objeto inmediato ridiculizar al adversario y que conoce su etiología en el estado psíquico pernicioso y no en la objetividad; o ya aquel que es inequívocamente expresión de una enfermedad mental del sujeto, es decir, manifestación de locura (risu insaniae). Otro tipo desviado, pero que no llega a caer en la enfermedad y, de ahí, perverso en la estimación del sujeto, es la risa vanitas purae, en la que se incurre desde la necedad y en la que se incluye la risa burlesca, la propia de la bufonada (scurrilitas). El análisis del fraile tiene como criterio de demarcación la correcta utilización de una prudencia ética, una frónesis dominada por la racionalidad como criterio antropológico de la calificación que pueda ser distinguida desde el punto de vista moral ${ }^{20}$. Aparece, pues, una inmersión analíticofenomenológica de las dos vertientes apuntadas por el pensamiento griego en la

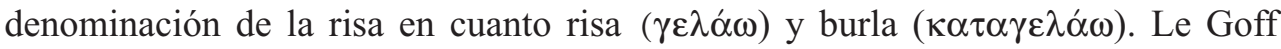
señala un nuevo aspecto de la risa en la lectura subjetiva con el término "sǔbrīsǔs", que implicaría algo así como "reír a hurtadillas o para dentro" 21 . La risa, por lo tanto, tomará caminos que recorren las páginas teológicas y la literatura del ámbito religioso, pero también la literatura más creativa (lo que no supone una lectura meramente alternativa a la religiosa, toda vez que en gran parte el mundo religioso invade todos los rincones del mundo medieval).

La naturaleza filosófica e intelectual de la risa conoce sus precedentes en las consideraciones que realizan los filósofos griegos clásicos, tanto el ateniense Platón en la República, como Aristóteles en la Poética, la Retórica y la Ética a Nicómaco. Sus aproximaciones van configurando los componentes reflexivos del mismo, a través de su expresión comunicativa asociada a las virtudes propias del hombre que vive en la polis. En cierto sentido, implican una reflexión sobre el constitutivo

\footnotetext{
20 S. Magnavacca, “Risus”, en Id., Léxico técnico de Filosofia Medieval, Miño y Dávila - Universidad de Buenos Aires, Buenos Aires 2005, 613-614. Cf. Guglielmo Peraldo, Summa virtutum acvitiorum (Gugliel Rovillium, Lugduni 1585).

21 J. Le Goff, Una larga Edad Media, Paidós, Barcelona 2008, p. 194. Cf. Id., "Rire au Moyen Age", en Les Cahiers du Centre de Recherches Historiques 3(1989), en formato electrónico desde el 13 de abril de 2009 disponible en http://ccrh.revues.org/index2918.html, consultado el 15 de febrero de 2011; Id., "La risa en la Edad Media", en J. Bremmer y H. Roodenburg (coord.), Una historia cultural del humor. Desde la antigüedad a nuestros días, Sequitur, Madrid 1999, pp. 41-54.
} 
antropológico de la risa, aunque no forma parte de su proceso anímico-racional, sino más bien socio-político - de ahí su ausencia en el De anima aristotélico-, pues la vida en sociedad y la comunicación que se establece mediante el logos que se asocia a ella, en sus aspectos sígnicos y comunicativos, son propiedades esenciales y específicas de los hombres.

La risa es expresión del humor, y el humor una estrategia del discurso. Cicerón, ya en pleno periodo grecorromano, ahonda estos aspectos, enriqueciendo la filosofía aristotélica en un discurso político que, sin olvidar el patrimonio de la filosofía griega, extiende sus raíces a la nueva geografía político-social que se establece con el fin de las polis y el helenismo y queda profundizado en la impronta del derecho y la administración social y estatal del mundo romano. Así, en las obras De officiis y De oratore, el filósofo romano manifiesta el carácter instrumental en el discurso de la risa (argumentum risibile). En la segunda de las obras citadas, Cicerón propone cinco cuestiones sobre la risa: "primera, lo que es; segunda, de dónde procede; tercera, si es propio del orador hacer reír; cuarta, hasta qué punto; quinta, cuántos son los géneros de ridículo" 22 . El pensamiento ciceroniano será leído posteriormente en la Edad Media y, más tarde, en la época renacentista y humanista, enriquecida con la incorporación de otras obras retóricas como la Institutio oratoria de Quintiliano.

Los precedentes, que podemos llamar, clásicos vinculan la risa al humor y la palabra al arte de la retórica, es decir, a una de las fuentes de la formación básica escolar. Y como acontecimiento de la naturaleza humana manifiesta su carácter estructural en el hombre, es decir, el hecho de ser una "capacidad" del ser humano, más allá de las consecuencias morales del uso emprendido. La risa, asociada al humor, supone la muestra evidente de la capacidad humana para enriquecer el discurso de la palabra en un logos que incluye el arte del discurso en su referencia social y política. Es evidente que dicho uso puede tener consecuencias en la construcción de un tipo de sociedad y establece una valoración del mismo hombre como ser "capaz" de realizar algo. Pero esta ya es una reflexión que tiene en cuenta la fundamentación axiológica de las capacidades y acciones humanas en sí (como hombre) y en relación a los demás en su proceso de sociabilidad. Esta cuestión, señalada por Platón, es retomada a partir de la inclusión del pensamiento cristiano, una vez que el mensaje cristiano entiende que el hombre se relaciona axiológicamente tanto con sus acciones y el desarrollo de sus capacidades, como en su ser referenciado al otro, sea especialmente al Otro trascendente, sea al otro de los iguales (al los otros hombres) que están, a su vez, en relación al Trascendente y transforman la "sociedad" en la que viven en "comunidad de creyentes", en ekklesia santa y reli-

22 "De risu quinque sunt, quae quaerantur: unum, quid sit; alterum, unde sit; tertium, sitne oratoris risum velle movere; quartum, quatenus; quintum, quae sint genera ridiculi". Cicerón, De oratore, II, LVIII, 235. 
gada, es decir, en comunidad religiosa. En este sentido, la risa expresa un valor moral, una referencia axiológica, y exige una valoración que tiene como criterio de demarcación el fin al que apuntan las acciones de los hombres religiosos: la santidad de lo divino. En el análisis de la risa se legitima una lectura de extensión de la significación antropológica que a los aspectos asociados a la capacidad humana racional y comunicativa, incluye la fenomenología psicológica y la lectura moralizante. Esta conjunción de elementos es la que se expresa en la exposición del fraile dominicano G. Peraldo expuesta con anterioridad. Ahora bien, no se trata aquí y ahora, en la Edad Media, de un abordaje desde la psicología clínica o médico-fisiológica, sino de una explicación que tiene en cuenta la psicología filosófico-moral, donde la caracterología del comportamiento anímico humano se expresa en la teoría clásica de las virtudes (apareciendo de nuevo la huella platónica) leída desde el criterio prudencial y fundamental de la advertencia espiritual y la temática de la adquisición de la gracia religiosa y su correlativo negativo del pecado 23 .

En este camino de extensión conceptual de la risa como fenómeno humano de diversas dimensiones, no importan tanto las afirmaciones vertidas tomadas en sí mismas como un todo, como el hecho de la presentación de los diversos aspectos horizontales (de las diversas acciones humanas) y verticales (de sus referencias axiológicas y ontológico-teológicas). Así podemos ver como Isidoro de Sevilla afirma que el "Hombre es animal racional, mortal, terrenal bípedo y capaz de reír (... solo el hombre puede reir)" 24 , en una clara extensión conceptual de las significaciones y las acciones antropológicas. Una propiedad auténticamente humana, ejemplo para la lógica y la retórica, utilizada por los diversos autores medievales y escolásticos. Alcuino de York utilizará la capacidad de reír para hablar de la propiedad exclusiva en el ejemplo del hombre25. Podemos observar una cuestión de la humanidad en su significación encarnada -y su naturaleza referida a Dios- en Juan Crisóstomo al interrogarse sobre imposibilidad de la risa en Jesús 26 . El equilibrio de las posiciones entre la lectura de la naturaleza humana de Isidoro de Sevilla y en la lectura negativa de san Juan Crisóstomo desde la óptica de la prudencia política a partir de la atemperación de las virtudes de Platón, encuentra un camino de solución en la pedagogía como camino epistemológico de ecos morales, tal y como lo expresa Clemente de Alejandría, realizando otro aporte de profundización antropo-

\footnotetext{
${ }^{23} \mathrm{Al}$ respecto tenemos presente la obra de J. Horowitz - S. Menache, L'humour en chaire ..., op. cit. 24 "Homo est animal rationale, mortale, terrenum, bipes, risu capax [...] est enim solum hominis, quod ridet”. Isidori Hispalensis Episcopi, Etymologiarum sive Originum. Liber II. De Rhetorica et dialecti$c a, 25,3)$.

25 "Ut, solius hominis proprietas est, risibilis esse". Alcuinus, De Dialéctica, 2, 5.

26 PG 62, col. 69. Cf. Th.N. Zeses, " "Voi ridete, a me invece viene da piangere': teoria e prassi del riso in Giovanni Crisostomo", en C. Mazzucco (ed.), Riso e comicità..., pp. 249-259; J. Le Brun, “ 'Jésus-Christ m'a jamais ri': analyse d'un raisonnement théologique", en Homo religiosus: Autour deJean Delumeau, Fayard, Raris 1997, pp. 431-437.
} 
lógica. En el Pedagogo se apuesta así por la risa positiva ( $\gamma \varepsilon \lambda \alpha ́ \alpha \omega)$ desechando el

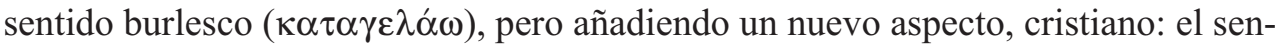
tido salutario, que inunda el devenir humano y, en ello, las pasiones (Isaac significa "el reír", ríe celebrando las fiestas del Señor [lo santo] y/o porque percibe la alegría de la salvación de la Iglesia ${ }^{27}$ ). La risa, por lo tanto, empieza a cargarse de una connotación moral vinculada a su estructura psicológica que no siempre tiene una significación negativa.

Un claro ejemplo de la importancia de la fuente histórico-salvífica como el lugar propio de la acción humana, la encontramos en un tipo de humor que considera de forma positiva la risa en su expresión incluso "burlesca" respecto al origen de la misma y que se expresa de forma privilegiada en los casos de martirio. Paradigmática de la época medieval, como lo refrenda el testimonio de J. de Voragine, es el caso, bien documentado de la leyenda del martirio de S. Lorenzo, quien en el momento de ser quemado vivo en la parrilla se permite burlarse de su torturador: Assum est, inqüit, versa et manduca ${ }^{28}$. La imagen del humor santo se expresará en otros de los contextos expresivos de la risa: el de la literatura. Así, el modelo de santidad que transmite la espiritualidad monacal se refleja en la literatura peninsular, por ejemplo, en Gonzalo de Berceo ${ }^{29}$. También el tono jocoso de la risa purificadora martirial es recogida por la literatura de Berceo de mano de la hagiografía de san Lorenzo, donde la actitud estoica de la narración de la antigüedad se ha transformado en actitud martirial:

[103] Las flammas eran vivas ardientes sin mesura, / ardié el cuerpo sancto de la grand calentura, / de lo que se tostava firvié la assadura, / qui tal cosa asmava non li mengüe rencura. / [104] «Pensaz», dice Laurencio, «tornar del otro cabo, / buscat buena pevrada, ca assaz so asado, / pensat de almorzar, ca avedes lazdrado; / fijos, Dios vos perdone, ca feches grand pecado» 30 .

27 "Isaac signifie «le rire»... Quelle autre occupation en effet convient à un être sage et parfait sinon jouer et se réjouir avec constance dans le bien et avec une belle organisation du bien, tout en célébrant des fêtes saintes avec Dieu? 2. On peut interpréter autrement la signification du texte prophétique: c'est nous qui nous réjouissons et qui rions à cause de notre salut, comme Issaac. Il riait, lui, parce qu'il avait été délivré de la mort; il s'amusait et il était dans l'allégresse avec sa femme, que es l'aide de notre salut, l'Eglise". Clemente de Alejandría, Le pédagoge, I, c. 5, 22, 1-2 (intr. y not. H.-I. Marrou, trad. M. Harl, Col. Sources Chrétiennes, 70, Cerf, Paris 1960, pp. 159-151).

28 J. de Voragine, La Légende dorée, tomo 2, Paris 1967 (éd. É. Rouveyre, 1902), p. 73. Una edición más nueva en Jacques de Voragine, La Légende dorée, ed. de A. Boureau, Gallimard, Paris 2004. Cf. E.R. Curtius, La littérature européenne et le Moyen Age, PUF, Paris 1956 (reimp. 1986. Ed. original: Europäische Literatur und lateinisches Mittelalter, A. Francke, Berna 1948), pp. 199-206.

29 "[89] Pon nulla jonglería non lo farién reyr,/nin liviandad ninguna de la boca deçir". G. de Berceo, Vida de Santo Domingo de Silos, en Obras completas de Gonzalo de Berceo, ed. C. Clavería - J. García, Fundación José Antonio de Castro, Madrid 2003, p. 388. Cf. F. López, "La poética de la risa en la literatura castellana medieval”, Foro hispánico: revista hispánica de Flandes y Holanda, 19 (2001) 11-21.

30 G. de Berceo, Martirio de San Lorenzo, en Obras completas..., op. cit., p. 506. Cf. M.J. Bayo, "De Prudencia a Berceo. El tema del martirio de Lorenzo", Berceo, 18 (1951) 5-26. 
Desde la etiología salutaria y santa como lectura religiosa de la tematización clásica puede entenderse que la comunidad religiosa (monástica) tenga que guardar el equilibrio en la justa expresión de la risa, de modo que, aun siendo una característica humana que expresa su sociabilidad, no ha de olvidar el carácter religioso de toda sociedad en cuanto comunidad, más aún en el mundo cenobítico (de la comunidad monástica). De ahí que en este contexto, desde san Pacomio hasta san Benito (con excepciones especialmente ocurridas en el contexto de búsqueda interna y necesidad de signos sociales diferente de los Padres del Desierto ${ }^{31}$ ), se previene con mayor insistencia ante el peligro de la risa como espacio de la nimiedad. Este último, en su regla - que se convierte en el modelo de vida religiosa medieval-se cuida mucho de subrayar esta prevención. Efectivamente, en un mundo dominado por el contexto indubitable de la cristiandad se busca en el interior los elementos de profundización de la comunidad religiosa (cosa muy distinta de lo que sucederá con el advenimiento del mundo de la ciudad, y más aún en una época en la que se tendrá que manifestar lo exterior hacia fuera para señalar apologéticamente, casi en un esfuerzo misionero, lo que es el hecho cristiano como acontece en el Barroco). De ahí, las advertencias de la regla benedictina: "no ser amigo de hablar mucho, 53. no decir necedades o cosas que exciten la risa, 54. no gustar de reír mucho o estrepitosamente"32.

La risa, en su enriquecimiento de matices antropológicos y sus vinculaciones externas, horizontales y verticales, aparece como el resultado de una pasión interna. En esa pasión el horizonte axiológico fundamental es el temor debido a Dios. La vida monástica exige, especialmente, la moderación de la risa en aras al bien espiritual interno, pero, también, a la significación externa, social o comunitaria, de la misma. Ahora bien, si la risa significa una vinculación a Dios, entonces es exaltada. Cuando en la época escolástica, ya en pleno siglo XIII, la experiencia monástica rompa los muros del monasterio para centrarse en el convento como lugar de comunidad en la vida ciudadana (como alternativa a la vida cenobítica), existirá un equilibrio entre la tensión del momento de cambio que se refleja en la risa: entre la seriedad y la racionalidad expresada en la vida religiosa y en la explicación teológica de las pasiones. Así podemos entender la recomendación de san Francisco de Asís de no deleitarse en palabras ociosas y vanas que conducen los hombres a la risa 33 .

31 "No me hables nunca de un monje que jamás se ríe. Ese no es un monje serio". R. Kern, Arguzie e Facezie dei Padri del Deserto, Ed. Piero Gribaudi, Turín 1986, p. 107.

32 F. Trisoglio, "Il riso nelle regole monastiche e negli scritti ascetici", en C. Mazzucco (ed.), Riso e comicità..., pp. 695-736. Cf. F. Pessotto, "Riso e comicità nel Cristianesimo antico", Quaderni medievali, 60 (2005) 69-178.

33 "(1) Beatus ille religiosus, que non habet iucunditatem et laetitiam nisi in sanctissimis eloquiis et operibus Domini (2) et cum his producit homines ad amorem Dei cum gaudio et laetitia (cf. Ps 50,10). (3) Vae illi religioso, qui delectat se in verbis otiosis et vanis et cum his producit homines ad risum". 
La cuestión de la risa se circunscribe desde la teología al "Tratado de las pasiones del alma" 34, como aparece de forma paradigmática y significativa en la I-IIae de la Suma Teológica de Tomás de Aquino, donde, tras estudiar las pasiones en general (q.22-25), sigue el estudio de las pasiones en particular (qq. 26-48). Es necesario precisar que la vinculación de la risa a la teoría de las pasiones supone, de hecho, la constatación de la prevención contra la irracionalidad; y que en el prisma cristiano, desde una lectura que tienen en cuenta el pensamiento clásico (platonismo, aristotelismo y estoicismo), la risa conoce una inyección de profundidad humana, de forma que ya en san Agustín forma parte del ser humano35. El control de las pasiones y de los signos como la risa no tienen como finalidad última el desarrollar una técnica de control (apatheia) contra el sufrimiento de la parte irracional, sino que tiene como finalidad el abandono del hombre al amor eterno, trascendiendo el placer y el dolor ${ }^{36}$. Tomás de Aquino, en buena lógica cristiana y en el ambiente intelectual de su época -desde Aristóteles-, equilibra la tensión dinámica platónica entre razón y pasión, donde esta obedece a la lógica de lo concupiscible y lo irascible ${ }^{37}$, intentando superar en este aspecto las advertencias de Alberto Magno, quien había ya reparado en que la división tripartita del alma (racional, irascible, concupiscible) implicaba una doble lectura según se leyera desde la tradición de los autores antecesores del occidente cristiano o desde los ojos de Aristóteles ${ }^{38}$.

Más allá de la "teoría de las pasiones", existen otros contextos donde la risa aparece vinculada al humor. En la literatura o la exposición popular $-\mathrm{y}$ en el contexto cristiano- los principios expuestos hasta ahora se presentan de forma distinta, pero no se anulan. De hecho, existen ya en la época visigótica, lecturas cristianas de fies-

San Francisco de Asís, Admonitiones, XX. (ed. bilingüe, introd. de J. Meseguer, eds. I. Rodríguez y A. Ortega, $2^{\text {a }}$ ed. revisada por J. García, Ed. Espigas - Publicaciones del Instituto Teológico de Murcia, Murcia 2003, p. 390).

34 Sobre las pasiones del alma y las emociones en la Edad Media se han publicado en los últimos años una buena colección de estudios. Cf. B. Bernier - P.-F. Moreau - L. Renault (eds.), Les Passions antiques et médiévales. Théories et critiques des passions, PUF, Paris 2003; S. Knuuttila, Emotions in Ancient and Medieval Philosophy, Oxford University Press, Oxford 2004; B. Rosenwein, Emotional Communities in the Early Middle Ages, Cornell University Press, Ithaca-Londres 2006; P. Nagu (ed.), Émotions médiévales, Critique, 716-717 (2007); P. Nagy - D. Boquet (dirs.), Le sujet des émotions au Moyen Âge, Beauchesne, Paris 2008; G. Burlando (ed.), De las pasiones en la filosofia medieval. Actas del X Congreso Latinoamericano de Filosofía Medieval, SIEPM - Pontificia Universidad Católica de Chile, Santiago de Chile 2009.

35 Cf. De civitate Dei, XIV, 9.

36 H.U. Von Balthasar, La Gloire et la Croix, IV, Aubier, Paris 1981, p. 108.

37 Cf. M. Meyer, "Le problème des passions chez saint Thomas d'Aquin", Revue internationale de philosophie, 48 (1994) 363-374.

38 Cf. P. Michaud-Quantin, "La psychologie dans l'enseignement au XII siecle", en L'homme et son destin, d'après les penseurs du Moyen Age. Actes du Premier Congrès international de philosophie médiévale. Louvain-Bruxelles, 28 août - 4 septembre 1958, Nauwelaerts, Louvain-Paris 1960, pp. 401-415. 
tas paganas donde el humor y la provocación de la risa o elementos teatrales cobraban su protagonismo, incluso de forma que las expresiones de la presencia del cristianismo en el mundo cotidiano y en el ritmo de la vida también se reflejarán en la liturgia, incluso la eucarística: "Las gentes -apunta Lázaro Carreter-acudian al templo a orar, sí, pero también a «divertirse»; muchas de sus costumbres paganas o folklóricas son llevadas a él para crear en torno a la misa un extraño complejo sacro-profano del que es difícil formarse una idea exacta"39. En este caso cuando existe una advertencia desde la jerarquía de la Iglesia, no es tanto por utilizar el humor y la risa, cuanto por olvidar el fin del deleite litúrgico cayendo en abusos 40 . La risa en este tiempo es un elemento de representación social y litúrgica que pasará a los Colegios universitarios en el siglo XIII donde la dramatización, y en ella la comedia, acompañaba el calendario litúrgico ${ }^{41}$, haciéndose cada vez más presente en la vida universitaria.

Esta es una muestra más de la importancia de la diversidad de planos que va a ir desarrollándose con el paso del tiempo, con la pluralidad de racionalidades -más allá de la escolástica (teológico-filosófica)-, con el advenimiento del Humanismo en la época del Renacimiento, con el empacho del racionalismo en la época del Barroco. Desarrollos temporales que tienen una línea de continuidad con la apertura antropológica operada a lo largo de la Edad Media, porque señalar "otros planos" no implica olvidar el hombre. Una pluriformidad de ópticas que son la extensión semántica de las disciplinas y que se refleja en el testimonio de la teoría de las pasiones, de forma que el discurso se va extendiendo a otras disciplinas como la psicología, la ética, la medicina y los diversos ámbitos de la teología 42 . La Edad Media, evidentemente, aún seguía en la órbita de la reducción psicológica en la profundización del estudio del hombre. Pero su apertura psicológico-moral, con las tensiones propias de toda evolución, va dando lugar a la ampliación de la mirada sobre el hombre construyendo de forma embrionaria una adecuada reflexión que va constituyéndose propiamente antropológica.

\footnotetext{
39 F. Lázaro, Odres nuevos: clásicos medievales en castellano actual. Vol. VIII. Teatro Medieval, Editorial Castalia, Madrid 1958, p. 15.

40 Cf. A.Ma Álvarez, “Aportaciones al estudio del teatro medieval en España”, El Crotalón, 2 (1985) 13-35.

41 J. Menéndez, Los jesuitas y el teatro en el Siglo de Oro, Universidad de Oviedo, Oviedo 1995, p. 21. Cf. F. Bertini, "La commedia latina del XIII secolo", en L'eredità clássica del Miedio Evo: Il linguaggio comico, Atti del Convegno di Viterbo, Agnesotti editore, Viterbo 1979, pp. 83-60.

42 "La dispersion du discours médiéval sur les passions nous conduit à examiner des textes que appartiennent à différents domaines: psychologie, éthique, théologie, médicine, mystique, pastorale". C. Casagrande - S. Vecchio, "Les théories des passions dans la culture médiévale", en P. Nagy - D. Boquet (dirs.), Le sujet des émotions..., p. 108.
} 


\section{La risa en la época de la Segunda Escolástica}

La pluralidad y diversidad que apunta la Escolástica en el contexto medieval pasa a la Segunda Escolástica, pero con variaciones. Dichas modificaciones son lógicas en la dinámica del pensar y justifican una historia del pensamiento. No sólo evidencian las transformaciones que se realizan en los comentarios de los maestros universitarios, sino que explican mejor la originalidad de dichos comentarios: muestran la tensión existente en todo ejercicio mental de tradición, contexto vital y perspectiva de futuro. En nuestro caso, la referencia a la cuestión de la risa de Suárez sirve como muestra de un camino que prepara la transición a la modernidad desde la tradición medieval, el ambiente Humanista y Barroco, y en una perspectiva que no podemos ya desdeñar ni decir que no es, a su vez, moderna (sin ser la modernidad).

\subsection{La referencia de Suárez: De anima, V, c.5, nn.11-14 (Disp.11, q.2 nn.8-10) ${ }^{43}$}

Francisco Suárez tratará sobre la risa en el comentario al De anima de Aristóteles. En la obra aristotélica no se trataba del fenómeno de la risa, la presencia de la misma en el comentario del doctor Eximio tiene un contexto doctrinal y/o pedagógico en sus propios compañeros maestros de Coimbra y un contexto de formación de la sensibilidad humanista que explica la presencia de este fenómeno. De forma que podemos ver una evolución desde el tratamiento tomista apegado a la doctrina sobre las pasiones, pasando por la mención jesuítica de los maestros de la Universidad de Coimbra -ya en un comentario al De anima de Aristóteles- de evidentes tintes humanistas, en un contexto antropológico y de tintes fisiológico-psicológicos, hasta la referencia de Suárez que asume la fuente conimbricense y su vinculación a las pasiones; prefigurando desde la ortodoxia católica las inquietudes cartesianas, en una lectura barroca del pensamiento teológico. Ello explica mejor el alcance de los pensadores de la Península Ibérica, no en tanto precartesianos, sino en cuanto constructores por sí mismos de una filosofía y una ciencia teológica a la altura de su momento histórico-doctrinal. Lo que realizará Descartes no podría entenderse sin este camino recorrido (aunque no se pueda reducir a él). Por lo tanto, estos autores no son precartesianos como Descartes no es postsuareciano, forma parte de la evolución lógica del pensar humano en el contexto que toca pensar.

\footnotetext{
43 Franciscus Suárez, De anima, lib.V, c.5, nn.11-14 (Opera omnia, ed. Vivès, III, Parisis 1856, pp. 767-768). La numeración Disp.11, q.2 nn.8-10, según la edición crítica de Salvador Castellote: Francisco Suárez, Comentaria una cum quaestionibus in libros Aristotelis "De anima", introd. y ed. crítica S. Castellote, T. III, Fundación Xavier Zubiri, Madrid 1991, pp. 88-89, disponible en formato pdf en la página web: http://www.salvadorcastellote.com/investigacion.htm. El link del documento pdf es: http://www.telefonica.net/web2/salcascu/deanimav3.pdf
} 
Los números 11 al 13 del capítulo quinto del libro quinto del Comentario suareciano al De ánima recogen la temática de la risa: 11. De passione risus, in quo consistat. Unde causetur, altercantur Veleriola et Fracastorius [...] 12. Valeriole argumentum [...] 13. Admiratio et gaudium qua ratione causent motum risus Passio risus libera est. Le sigue el n. 14. De passione fletus, contrapartida de la risa44.

Estos números están incluidos en una discusión sobre los actos sensitivos del apetito (Caput V: quotnam sint, et quales actus sensitivi appetitus) encuadrando la risa en las "Pasiones concupiscibles" (De Passionibus concupsicibilis).

En el artículo 11 (De passione risus, in quo consistat. Unde causetur, altercantur Veleriola et Fracastorius) Suárez inicia con una definición descriptiva de la risa desde el punto de vista fisiológico, si bien se plantea una cuestión de duda al respecto: "Risum constat proxime consistere in vibratione quadam septi transversi, et musculorum thoracis, atque oris: causatur autem in motus ex interiori aliqua animi motione: quae vero illa sin, non convenit inter auctores". Le sigue inmediatamente una reflexión sobre la causa de la misma, lo que lleva a alguien a reír, en este caso como efecto de la pasión, como actividad visible de la delectación y la alegría (ex delectatione et gaudium). Sobre el tema de la alegría también surgen dudas si tenemos en cuenta las valoraciones de los especialistas en medicina y fisiología, en especial, las valoraciones realizadas por François Valleriola y Girolamo Frascastoro. Para el primero, en contra del segundo y de Francisco Vallés, la alegría no es causa suficiente para provocar la risa, la risa es resultado del "cosquilleo" (pero aquí surge una cuestión: ¿cómo el cosquilleo puede ser causa de risa solamente, cuando la experiencia muestra que al hacernos cosquillas a nosotros mismos no nos produce esa acción ninguna risa?). Para Fracastoro la alegría es causa de la risa. Para Valles la risa es resultado, especialmente, de la admiración. Los locos y estúpidos ríen por nada, y vemos que los niños ríen más porque se admiran más y de esta forma es más fácil que se deleiten. La admiración en sí no causa la risa ni el deleite en sí, sino la acción conjunta de la admiración y la alegría. Suárez argumenta que podemos dar por razonable la explicación del primero, lo que no niega lo que Vallés ha afirmado respecto de la admiración, pues el cosquilleo, causa fisiológicosensible de la risa, provoca rápidamente en el alma una admiración y un deleite ${ }^{45}$. Siendo esto posible, Suárez tratará (n. 13) de conjugar la aclaración fisiológica con la causa médico-anímica o psicológica. La respuesta lleva a Suárez a afirmar que la causa nace en la conjunción (consenso y simpatía) de la facultad natural, vital y

\footnotetext{
44 Ibid., V, c.5, n.11 (ed. Vivès, pp. 767-768).

45 "Dicendum ergo titillationem, ut causet risum, furtivam esse oportere et repentinam, atque ita simul admirationem causare, et delectationem: nam partes, in quibus sit titillatio, sunt acutioris tactus, atque hoc insinuat Aristoteles...". Ibid., V, c.5, n.12 (ed. Vivès, p. 767).
} 
racional46. Existe, de esta forma, una posibilidad de que la pasión libere el alma, dependiendo de la voluntad.

La respuesta y la cuestión tienen implicaciones filosóficas que vamos a ir señalando, de forma especial, al final. En todo caso, aparecen aquí apuntadas varias cuestiones que nos pueden servir de guía en la explicitación de la evolución del pensamiento escolástico-humanista de lecturas medievales, en un contexto prefigurador de la modernidad y que nos sugiere algunas consideraciones. Como hemos mencionado, la primera novedad que nos viene a la cabeza sobre las reflexiones de la escolástica medieval respecto de la risa y la tradición anterior, es el hecho de que aparezca en un comentario al De anima; ello nos empuja a pensar sobre la evolución, tanto de la presencia humanista en la escolástica del siglo XVI. Lo que nos ayudará a comprender mejor el porqué de este cambio.

Viendo los enunciados del tratado, llama también la atención la mención primera a la cuestión médico-fisiológica, en este caso a partir de las presentaciones de Valleriola y Fracastorio, lo que invita a repasar, siquiera epidérmicamente, lo que se conoce bajo el nombre de (3.3.) "humanismo médico-científico" como un contexto necesario en el que entender las afirmaciones de Suárez.

Por último, la recuperación de la relación no solo apetitiva, sino pasional, de la risa (en cierta forma no tan subrayada en el comentario de los maestros jesuitas de Coimbra) nos llevará a una reflexión breve a modo de conclusión a la referencia a la admiración (4), que como señalamos anteriormente al recordar a Descartes, suponía un elemento de distanciamiento decisivo respecto de la doctrina tomista.

\subsection{El humanismo en la Escolástica}

La ubicación de la referencia de la cuestión de la risa en un comentario al De anima es original respecto de la óptica medieval precedente, así como la utilización de un contexto fisiológico y médico, de la misma forma que resulta de gran interés la evocación causal a la admiración. Estos tres elementos siendo en principio originales para el lector, no constituyen en sí una novedad absoluta, especialmente en lo que se refiere a los dos primeros. Y conocen una lógica de la evolución del pensamiento escolástico. Y en ello podemos señalar un escalón intermedio como es el comentario a la obra de Aristóteles realizada en Coimbra, por los maestros de la Compañía de Jesús, en los últimos años del siglo XVI. El Curso Conimbricense refleja el diálogo permanente de la escolástica, más allá de sus aciertos y limitaciones, con el ambiente intelectual de su época: en especial el Humanismo, operando un cambio hacia el Barroco.

\footnotetext{
46 "Ac dicendum, causam esse naturales consensionem et sympathiam facultatum naturalium, vitalium et rationalium”. Ibid., lib.V, c.5, n. 13 (ed. Vivès, p. 767).
} 
La evolución de la Segunda Escolástica que tiene como epicentro lo que conocemos con el nombre de "Escuela de Salamanca" se realiza en diálogo directo con el Humanismo en una época que va del Renacimiento al Barroco. Si es verdad que este encuentro dispar y de no pocas críticas mutuas se encuentra muy presente, especialmente desde el Humanismo hacia la escolástica, no es menos cierto que no se observa una radical separación entre la labor realizada por el humanista y la que efectúa el teólogo. La interacción es mutua y existen diversos episodios o "lugares" donde se visualizan mejor, como, por ejemplo, la influencia de la filología en la exégesis bíblica ${ }^{47}$. La teología encuentra en el Humanismo, de forma consciente o inconsciente, un espejo donde mirar su propio quehacer y supondrá un revulsivo de renovación. Del diálogo establecido entre ambos surge una preocupación por las bases de la tarea teológica que sepa equilibrar las aportaciones humanistas con la ortodoxia que recorre los centros de estudios eclesiásticos ${ }^{48}$. Como resultado de esta reflexión en y desde el contexto humanista se desarrolla una inquietud propia, una forma cristiana de expresar los valores humanistas ("Humanismo ortodoxo o cristiano"49) que intenta superar una posición definida por la dicotomía entre las nuevas formas de entender el influjo de las letras nacidas de la época clásica y la tradición escolástica medieval. Si bien el Humanismo construía su identidad en la medida que se alejaba de las formas y contenidos propios de la enseñanza universitaria de tradición escolástica, no es menos cierto que en su influjo sobre los maestros de las instituciones educativas, iban operando la transformación del propio método teológico, lo que llevó a admitir variaciones de tonos en la exposición del contenido curricular. La escolástica medieval lejos de agotarse se revitalizó en un segundo impulso, un renacimiento metodológico que iría preparándose en el siglo

47 Cf. N. Fernández - E. Fernández, Biblia y Humanismo, textos, talantes y controversias del siglo XVI español, Fundación Universitaria, Madrid 1997.

48 Sobre la relación entre el primer humanismo y la escolástica por los territorios peninsulares cf. M. Andrés, "Humanismo español y ciencias eclesiásticas (1450-1565)", en Repertorio de Historia de las Ciencias Eclesiásticas en España. Vol. VI, Instituto de Historia de la Teología Española-Universidad Pontificia, Salamanca 1979, pp. 111-142. Sobre la introducción del humanismo en Portugal podemos ver una visión amplia con una profusa bibliografía en J. Martins, Humanisme et Renaissance de l'Italie au Portugal: les deux regards de Janus, 2. Vols., Fundação Calouste Gulbenkian, Paris 1989. 49 Cf. una posición de más separación en L. Gil, Estudios de humanismo y tradición clásica, Universidad Complutense, Madrid 1984 (cap.: "Gramáticos, humanistas, dómines"). Por su parte, la tesis más conciliadora en J. Pérez, "Renacimiento y escolástica", en V. García de la Concha (ed.), Literatura en la época del Emperador, Ediciones Universidad de Salamanca, Salamanca 1988, pp. 920. Sobre este tema cf. M. A. Pena, La Escuela de Salamanca. De la Monarquía hispánica al Orbe Católico, BAC, Madrid 2009, pp. 9-12. Otros estudios que podemos mencionar: J. Belda, «Teología y Humanismo en la Escuela de Salamanca del siglo XVI», in Confrontación de la Teología y la cultura. Actas del III Simposio de Teología Histórica (7-9 mayo 1984), Facultad de Teología san Vicente Ferrer, Valencia 1984, pp. 169-174; Id., La Escuela de Salamanca y la renovación de la teología en el siglo XVI, BAC, Madrid 2000, pp. 243-311. 
XV hacia una Segunda Escolástica, de coloración propia, que va constituyéndose en una nueva lectura del material teológico. Sus "Comentarios" proyectan también esa innovación con la relectura del material clásico que ya se utilizaba, pero que ahora tenía una mayor riqueza de fuentes; una lectura clásica que expresa, sobre todo, una sensibilidad cultural renovada y que se irradia en aspectos antropológicos, pedagógicos, metodológicos que no escapan a la propia renovación metafísica. Así, la teología intenta responder de forma interna a los retos que el humanismo pretendía presentar desde una lectura "auténtica" del legado clásico, como herramienta específica para una renovación pedagógica exigida por la sabiduría que le era propia al nuevo hombre renacentista. Un hombre exigido por la vivencia de su naturaleza, por la fuerza de su palabra y la potencia de sus pasiones 50 . "En definitiva -concluye J. Belda- estamos ya ante una renovación madura de la Teología Escolástica, que, depurando a fondo los defectos anteriores y apropiándose las buenas aportaciones de la cultura humanista, da como resultado una sana Teología moderna, adaptada a las necesidades de los nuevos tiempos, que raya a gran altura [...] una Teología Escolástica y Humanista al mismo tiempo, que sin renunciar a sus esencia íntima como ciencia de fe, sin embargo sabe estar a la altura de las circunstancias, acogiendo de buena gana las exigencias culturales y científicas del momento, e incorporándolas de manera prudente y equilibrada a la labor teológica, sobre todo en lo referente a la vuelta a las fuentes bíblicas y patrísticas" 51 .

El ineludible diálogo de la escolástica con el Humanismo va realizándose de forma específica en los diversos centros educativos; una misión inexcusable, especialmente para la identidad de la catolicidad, y que exige nuevas formas religiosas $\mathrm{y}$, en ella, una nueva metodología. Es la expresión del cambio definitivo del mundo en todas sus facetas y que se encarnará en el protagonismo religioso. Las órdenes

50 "El Humanismo no puede ser, por tanto, reducido a la espiritualidad erasmista, laica, reformada u otras formas de devotio moderna, ni tampoco al ejercicio retórico y literario de escribir en latín, ni siquiera a la filología y crítica de los textos clásicos; el Humanismo renacentista, al arruinar la concepción unitaria del sentir y del sentir medieval, propició la conformación de un nuevo modelo mental, humano por contraposición, en que la vuelta (imposible) a la Antigüedad y la recuperación del legado clásico se sentían más bien como instrumentales de la nueva paideia, sea en la búsqueda de la elegantia en el decir o de la superioridad en el saber, supuesto que «en los antiguos estaba la sabiduría». La nueva epistemología impulsa el sentimiento de la vida humana como realidad plena, de la que los clásicos proporcionaban el aparato o la máquina para conseguirla, $\mathrm{y}$, aunque con una visión cada vez más histórica del pasado, siempre dentro del marco de una concepción providencialista, teocrática, supernaturalista, del devenir humano, en que aquel quedaba integrado. En nuestra situación, lo particular del momento es, pues, que esa tensión entre lo antiguo y lo moderno se resuelve en la creación de un discurso vernáculo propio y original, que asimila la espiritualidad tradicional a las nuevas nociones y formas de pensamiento. Y esto no parece que pueda ser objeto de controversia". V. Bécares, Guía documental del libro salmantino del siglo XVI, Fundación Instituto Castellano y Leonés de la Lengua, Burgos 2006, p. 13.

51 J. Belda, La Escuela de Salamanca ..., op. cit., p. 311. 
religiosas que supusieron un cambio en la mentalidad medieval en el siglo XIII en una órbita de Renacimiento (leyeron de forma ejemplar las bases del renacimiento carolingio, exploraron el renacimiento de la baja Edad Media en los siglos XII y XIII, y acompañaron las exigencias y los debates en el llamado Renacimiento de los siglos XV e inicios del XVI), daban paso, poco a poco, a través del ambiente humanista a otra nueva forma exigida por las novedades del Nuevo Mundo, no solo el descubierto geográficamente ad extra, sino el revelado espiritualmente ad intra (fuera en sus formas ortodoxas, místicas o reformadas). Ignacio de Loyola es el protagonista religioso que personifica esta nueva exigencia. La Compañía de Jesús siguiendo el espíritu de su fundador y sus inquietudes respecto a la formación del cristiano, insistirá de forma privilegiada en la lectura de la Tradición doctrinal cristiana en tiempos de humanismo y reforma. Ello supone una profunda instrucción: "Todo el bien de la cristiandad y de todo el mundo depende de la buena instrucción de la juventud", escribió Ignacio de Loyola a Felipe II ${ }^{2}$. Traemos a la memoria estos hechos para poder comprender y contextualizar los cambios que se observan en el texto del doctor Eximio y que no nacen de la casualidad, sino de un proceso propio del dinamismo de la historia del pensamiento. Y es que el desarrollo efectivo de la formación supondrá estar atento, aún más si cabe que en otras órdenes, ante los nuevos retos que se presentan y por ello exigirá que los maestros jesuitas tengan en cuenta las necesidades formativas y pedagógicas necesarias para elaborar una Reforma Católica efectiva. De esta forma, la Ratio atque Institutio Studiorum Societates Iesu reflejó en una red de centros de estudios repartidos por el orbe cristiano cada vez con más fuerza las indicaciones que Ignacio de Loyola había establecido y que valoraban una sólida formación en letras clásicas con una insistencia dignas de Erasmo o Vives ${ }^{53}$. No puede extrañar, pues, que en la obra jesuítica aparezcan elementos a los que eran sensibles las obras literarias, filosóficas y científicas de su tiempo 54 .

En lo que afecta a nuestro tema, la risa, estos elementos se visualizan en la presentación que realizan los maestros jesuitas de Coimbra en el conocido como Cursus Conimbricensis, en especial en el comentario al De anima (1599), III, c. XIII, q. 1, a. 6 (Dilutio alterius partis eiusdem argumenti; disputatio de risu) ${ }^{55}$.

52 R. García-Villoslada, San Ignacio de Loyola. Nueva biografía, BAC, Madrid 1986, p. 877.

53 M. Miranda, "Ratio Studiorum. Uma nova hierarchia de saberes", en Societatis Iesu, Código pedagógico dos Jesuitas. Ratio Studiorum da Companhia de Jesus. Regime escolar e curriculum de estudos, not., intr. e vers. port. M. Miranda, Esfera do caos, Lisboa 2009, p. 23.

54 No podemos entrar en la importante temática de la literatura sobre la risa como elemento también barroco, especialmente a partir de Rabelais. Cf. M.A. Screech - R. Calder, "Some Ranaissance attitudes to laughter", en A.H.T. Levi (ed.), Humanism in France at the end of the Middle Ages and in the early Renaissance, Manchester University Press, Manchester 1970, pp. 216-227.

55 Comentarii Colegii Conimbricensis S.I., In tres libros de anima, Aristotelis Stagiritae, III, q.XIII, a.VI, (Conimbricae, Typis \& expensis Antonij à Mariz, 1598, p. 422), (trad. en lengua portuguesa, 
Podemos observar ya esta evolución de la presencia humanista en el comentario aristotélico, de forma formal y material. Formalmente por el lugar en el que aparece: el comentario al De anima. Materialmente por los elementos que reflejan, diferentes al contexto tomista y prefiguradores del comentario de Suárez. La breve cuestión De risu se puede estructurar en tres partes donde aparecen elementos propios de la época medieval, pero tratados teniendo en cuenta y reteniendo en la retina la crítica del Humanismo. Así, el comentario de los maestros de Coimbra inaugura su exposición con una referencia que ya no aparece en el texto de Suárez, relativo al comentario De anima sobre la risa. Una definición de la misma dependiente de la Oratoria de Cicerón, que como hemos señalado con anterioridad, es uno de los referentes del significado de la risa en el contexto del desarrollo de las artes liberales y que en este momento de revitalización de la retórica y las técnicas literarias cobra aún más fuerza. A continuación aparece una referencia -que sí se muestra central en Suárez, pero en relación a cuestiones de disputa de la etiología médicobiológica y psicológica- respecto a los aspectos fisiológicos de la acción de la risa, citando como autoridad única a Girolamo Fracastoro. Tras el acercamiento humanista al fenómeno de la risa en su lectura retórica y su vertiente médica, los Conimbricenses revisan la relación de la risa a la actividad pasional, recuperando los elementos tradicionales: la risa nace en el alma (causa eficiente principal), provocado por el apetito en un proceso fisiológico determinado (causa instrumental) para provocar la expresión del gozo del alma (gaudium) y la alegría (laetitia).

El comentario de los maestros jesuitas de la universidad lusa de Coimbra supone un eslabón más en el camino de la elaboración del pensamiento que trasluce una vez más que los saltos en el vacío no suelen ser explicativos del quehacer intelectual humano. Las razones aquí expuestas reflejan la presencia humanista tanto en la valoración retórica como en la insistencia de una renovada inclusión de los aspectos médicos en el pensamiento filosófico. Una prefiguración de una antropología auténtica que sea capaz de ir abarcando la reflexión humana más allá de la psicología filosófica propia de la reflexión dualista nacida del horizonte griego, en el que los elementos espirituales quedan explicados en los tratados Sobre el alma y los corporales en las obras fisiológicas y/o médicas. Los jesuitas son conscientes de la importancia de incorporar lo que se conoce como "humanismo científico" a la mirada sobre el hombre, no pudiendo olvidar una visión única del hombre. Por razones que ahora no podemos entrar - sin duda nacidas de cierta visión de la antropología cristiana que necesita a partir de la noción de pecado ir señalando el equilibrio entre contingencia y libertad humana con la gracia divina, todo ello desde el contexto doctrinal de Trento- las autoridades académicas quisieron siempre atemperar estas

Comentários do Colegio Conimbricense da Companhia de Jesus, Sobre os três livros do Tratado Da Alma de Aristóteles Estagirita, trad. M. da Conceição Camps, intr., apênd., e bibl. M.S. de Carvalho, Lisboa, 2010, p. 555). 
inclusiones, como señala con claridad la Ratio Studiorum definitiva (1599) al afirmar que no se realicen en las facultades de Artes y Teología "digresiones sobre la anatomía u otras materias que son propias de la medicina" 56. A pesar de estas advertencias (que si se hacían es porque ya era notorio que el aspecto fisiológico y médico era introducido) las referencias van marcando un giro en la mentalidad antropológica que va, a su vez, retorciendo el propio espíritu Humanista.

\subsection{El debate del humanismo científico-médico}

Tanto el comentario jesuita al De anima del curso de Coimbra como el comentario de Suárez sacan a la luz un contexto médico-fisiológico que caracteriza, sin duda, su época. Efectivamente, las teorías nacidas de la antigüedad y las interpretaciones filosóficas de las teorías platónicas y aristotélicas, sumadas a la teología cristiana y el comentario humanista de autores como Cicerón, juegan un papel vital en torno a la óptica sobre la risa, especialmente en los teólogos. Pero en el conjunto intelectual del siglo XVI y en su precedente del Renacimiento las explicaciones sobre el acontecimiento de la risa se inspiran en los conocimientos médicos transmitidos en las diferentes obras. Esta época final del siglo XVI y principios del XVII refleja un periodo marcado por una percepción positiva de la fisiología y, en esta, por el interés en el aspecto corporal del hombre. G. De Rocher ha sintetizado con acierto lo que queremos señalar en las siguientes líneas:

[...] des écrivains tels que Rabelais et Noël du Fail, et des artistes protégés par François Ier à Fontainebleau, en portent témoignage, sans parler des penchants anatomiques d'un Michel-Ange ou d'un Léonard de Vinci. Plus tard, lors des conséquences sanglantes de la Réforme, anatomie et physiologie seront le centre de l'attention. La littérature de l'époque enregistre guerres et pestes, et on no doit pas s'étonner si la conscience contemporaine fixe son regard sur le corps de l'homme 57 .

La atención que Suárez realiza de Frascatoro y la disputa con Valleriola, así como la mención de autoridad de Vallés, es un signo de la extensión de la psicología clásica como elemento relevante dentro del análisis renacentista. No se trata tan solo de realizar una explicación de los contenidos y las perspectivas de Aristóteles o Tomás de Aquino, sino que junto a ellas son asimiladas las perspectivas más individualistas que tienen un ejemplo en la lírica de Petrarca o la subjetividad anímica de Ficinio, en una pugna entre el espiritualismo de la escuela de Florencia y la revi-

\footnotetext{
56 Societatis Iesu, Ratio Studiorum, IX (Código pedagógico dos Jesuitas. Ratio Studiorum da Companhia de Jesus. Regime escolar e curriculum de estudos, not., intr. e vers. port. M. Miranda, Esfera do caos, Lisboa 2009, pp. 138-139).

57 G. de Rocher, "Le rire de la renaissance: le Traité du ris de Laurent Joubert", Revue Belge de Philologie et d'Histoire, 56 (1978) 629-630.
} 
talización del "soma" en la visión naturalista de Pomponazzi, donde "la biología de Aristóteles [...] supera a la Metafísica"58. En los Conimbricenses la tensión por la parte humanista y la esfera intelectual de la retórica permanece como punto de partida -se trata de un comentario de 1598-. En la revisión efectuada por Suárez años más tarde, el inicio de la definición toma ya los tintes de la disputa médico-biológica. Inserto en una temática anímica y psicológico-moral, dentro de lo que se podría llamar un tratamiento clásico, a partir de la división tripartita del alma (que no era ajeno a la época en la que se había revitalizado el platonismo), sin embargo, el desarrollo ya comporta elementos propios de un momento de madurez renacentista e, incluso, de superación barroca. Aun con dificultad, la esfera biológica parece imponerse como lugar de discusión de la esfera psicológica. Es como si Suárez, animado por los precedentes de la Universidad de Coimbra que conocía tan bien, deseara reformular la tradición psicológico-moral con los elementos de fundamentación antropológico-biológicos, de forma que esta tradición adquiriera una nueva dimensión de "modernidad" y de "actualidad", al menos en su época. En este sentido, se observa en los comentarios de los maestros de Coimbra y en Suárez, la inclusión progresiva de la obra aristotélica donde trata los temas fisiológicos, como es el caso de Partes de los animales, en el tratado sobre el alma, manifestándose, una vez más, lo que venimos diciendo.

Sin duda alguna, existía un movimiento, con una cierta historia, que avalaba la apertura de miras hacia la revitalización del elemento corporal humano y que tenía como punto de inflexión la interpretación galénica. Dentro de la tradición médica que va imponiéndose, y en lo que nos interesa, es importante notar el impulso que Pietro Pomponazzi realizara en el estudio de la obra aristotélica sobre la fisiología corporal y animal. Durante el siglo XVI, a partir de la publicación de la obra del italiano (1521-1524) acontece toda una pléyade de estudios que suscitan diversas hermenéuticas en torno a diferentes frentes que van de la arquitectura escolástica y la filosofía humanista a los discursos sobre el alma, y que dan perfecta cobertura a esta práctica de la escolástica jesuítica59.

\footnotetext{
58 S. Castellote, "Introducción", en Francisco Suárez, De anima. Texto inédito de los doce primeros capitulos. Ed. bilingüe, introd. y ed. crítica por S. Castellote, Sociedad de estudios y publicaciones, Madrid 1978, p. LXXIII.

59 Stefano Perfetti ha estudiado este momento desde la publicación de la obra de Pietro Pomponazzi en Bolonia los años de 1521-1524 hasta el Commentaria in primum librum De historia animalum publicada en Frankfurt en 1601 señalando la fecundidad de los estudios en torno a tres núcleos temáticos: 1) arquitectura escolástica y la filología humanista (Pietro Pomponazzi, Niccolò Leonico Tomeo y Agostino Nifo), 2) nueva tradición exegética (Simone Porzio, Francesco Vimercato y Julius Caesar Scaliger) y, 3) discursos sobre el alma (Cesare Odoni, Daniel Furlanus, Cesare Cremonini y cristoforo Guarinomi). S. Perfetti, Aristotle's zoology and its renaissance Comentators (1521-1601), Leuven University Press, Leuven 2000 (Cf. bibliografía: pp. 233-249).
} 
La revitalización del aspecto mecánico-animal del cuerpo que va abriéndose paso tiene origen en la literatura científica española en un contexto fundamental filosófico-médico que suscitó reacciones importantes en su época y posteriormente. Nos referimos a la publicación de la famosa obra Antoniana Margarita de Gómez Pereira de importantes consecuencias en el pensamiento antropológico y psicológi$\mathrm{co}^{60}$. Las adhesiones, matizaciones y oposiciones que desatará dicha obra se inician en el mismo año de su publicación y se extienden a las realizadas antes y después de la obra cartesiana61. Sin duda, las reacciones que se realizan hasta la publicación de la obra de Descartes servirán en la propia reflexión del filósofo francés. Lo que la obra afirma se puede ver ad contrarium por las objeciones que se le plantean. Los primeros comentarios adversos, como nos relata J. L. Barreiro, vienen de la mano de autores como el catedrático de Teología de la Universidad de Salamanca Miguel A. Palacios, cuyas objeciones 62 son contestadas en la segunda edición de la Antoniana Margarita. Sus cinco apelaciones son relativas a las afirmaciones de Pereira afirmando que 1. los "brutos" carecen de sentido, es decir, son insensibles; 2. que el acto de sentir no es accidental respecto a la cosa en potencia, sino potencia de su sensación, es decir que no es potencialmente diferente de la facultad; 3. que el acto queda generado por la potencia, lo que supone afirmar que la potencia y el objeto son con-causales de la acción; 4 . que el sentido común no es potencia orgánica, ni potencia particular sino sentido común de la misma alma por lo tanto no diferenciadas del alma; 5. la materia prima es abolida, no se puede admitir63.

60 Gometius Pereira, Antoniana Margarita, opvs nempe Physicis, Medicis, ac Theologis non minvs vtile, qvam necessarivm, in officina Calchographica Guillielmi de Millis, Methynae Campi 1554; $2^{\mathrm{a}}$ ed. Nicolás Antonio, Francofurti 1610 y $3^{\circ}$ ed. Ex Typographia Antonii Marin, Matriti 1749 (ed. facsimiliar y traducción al español de la tercera edición donde aparecen las Objeciones y la Apología en: estudio preliminar y notas de J.L. Barreiro; trad. J. L. Barreiro, C. Souto, J.L. Camacho, Universidad de Santiago de Compostela - Fundación Gustavo Bueno, Santiago de Compostela 2000. Cf. R. Llavona - J. Bandrés, "Gómez Pererira y la «Antoniana Margarita»", en M. Saiz - D. Saiz (Coord.), Personajes para una historia de la psicología en España, Pirámide - Univ. Autònoma de Barcelona, Barcelona 1996, pp. 81-93). Sobre este autor entre otras referencias cf. J.T. Pastor, "Gómez Pereira", en M. Fartos - L. Velázquez (coords), La filosofía española en Castilla y León: de los orígenes al siglo de Oro, Universidad de Valladolid, Valladolid 1997, pp. 255-280.

${ }^{61} \mathrm{La}$ cuestión sobre la deuda intelectual de Descartes con Pereira es conocida. Al respecto cf. R. Llavona - J. Bandrés, "La recepción del pensamiento de Gómez Pereira en Europa del Barroco a la Ilustración", en Revista de Historia de la Psicología, 14 (1993) 131-137.

62 Michaelis a Palacios, Obiectiones Licenciati Michaelis a Palacios, Cathedrarij sacrae Theologiae in Salmantina Uniuersitate aduersus nonnulla ex multiplicibus Paradoxis Antonianae Margaritae, \& Apologia eorundem, officina chalcographica Guilielmi de Millis, Methynae Campi 1555. Ed. y trad. española en la misma edición de J.L. Barreiro del Antoniana Margarita, en la tercera edición donde aparecen las objeciones (cf. nota 59), pp. 304-318.

63 "I. [...] Bruta carere sensu. II. [...] actum sentiendi non esse accidens diversum re à potentia, sed potentiam esse sua sensionem. III. Vexatr te praetereà generationem actus ab objecto. IV. [...] sensum communem non esse potentiam organicam, neque potentiam particularem, sed ipsam animam esse 
Junto al teólogo Palacios otra temprana reacción lo constituye el anónimo atribuido a Francisco de Sosa Endecálogo contra Antoniana Margarita ${ }^{64}$, de hecho una sátira en la que un grupo de animales, que se sienten perjudicados al ser privados de sentidos acusan a Gómez Pereira de dicha amputación y deciden condenarlo (de la mano del portavoz, el cocodrilo) allí donde la obra fue divulgada.

Dentro de la originalidad de la obra de Pereira, plena de sugerentes intuiciones, podemos citar un texto en el que aparece formulada una crítica a la división tripartita del alma en el contexto del reproche que hace al sentido común, que sugiere el trasfondo del contexto en la tematización de la risa y la tensión de considerar la pasión dentro del esquema tradicional, antecediendo la variación realizada en Descartes:

Se rechazan las afirmaciones de Platón y Galeno sobre la pluralidad de almas en el hombre. De similar manera se rechazan las opiniones de Platón y Galeno. En efecto, todos disciernen que su concupiscencia no es su irritabilidad, ni su intelección, pero no lo habrían podido discernir si no desearan, ni se irritaran, ni inteligieran con un único sentido65.

Las afirmaciones de Pereira llevaban a una interpretación que termina en el automatismo animal y vislumbra el automatismo del cuerpo humano. Las reacciones y los ecos de la obra de Pereira se extienden así al campo de la reflexión médico-filosófica y a los propios escolásticos. De ello que aparezcan otras reacciones más profundas en obras que señalan el carácter tradicional de la literatura médica, pero que ofrecen variaciones y concesiones importantes desde la nueva perspectiva. Este tipo de reacción que se vierte en una nueva forma de investigación médico-filosófica es encarnado por el citado Francisco Vallés, quien realizará una crítica a la visión corporal y material del ser humano reflejado en la obra Antoniana Margarita. La obra de Vallés responde, a su vez, a un contexto de revisión de la obra galénica, crítica en la que Pereira es un elemento simbólico. La crítica que realizan los anatomistas del siglo XVI provocarán que los autores más cercanos a la autoridad aristotélica y galénica tengan que aceptar otras fuentes y sopesar sus afirmaciones. Con el recordatorio de Vallés nos reconducimos de nuevo a nuestro tema.

Recordemos que Francisco Vallés (1524-1592) fue profesor de un centro universitario tan renacentista como la Universidad de Alcalá. El autor del

sensum communem. V. Materiam primem negas, continuò concedis elementa simplicia, citrà illam compositionem materiae et formae". Ibid.. (ed. J.L. Barreiro, pp. 306, 311, 313, 314, 315).

64 Francisco de Sosa, Endecalogo, (sic) contra Antoniana Margarita, Matheo del Canto, Medina del Campo 1556. Ed. española de P.M. Cátedra, Ed. Delstres, Barcelona 1994.

65 "Plato et Galenus improbatur de plurium animarum in homine assertione. Cec alio modo Plato et Galenus improbantur. Omnes enim decernunt suum appetere, non esse suum irasci, neque suum intelligere, quod efficere non valuissent, si aliquo uno non appeterent, irascerentur, et intelligerent". Gometius Pereira, Antoniana Margarita (ed. Barreiro, p. 62). 
Controversiarum medicarum et philosophicarum fue médico de la casa real de Felipe II, considerándose, uno de los mayores exponentes de del Humanismo médico renacentista, pionero de la anatomía patológica 66 . La ventaja de Francisco Vallés, posiblemente lo que le valió su fama y la utilización como argumento de autoridad, es el carácter crítico y tradicional a la vez. No dudará, cuando sea necesario de realizar correcciones a las aportaciones de Galeno, sin que ello impida que este sea visto como justo seguidor de Hipócrates. El equilibrio de las fuentes que se amplia a elementos de filosofía natural, filosofía humanista, medicina y un estilo humanista provoca que sea una obra que no pase desapercibida para Suárez. También el hecho de que Vallés realice una disputa entre el origen de la risa en relación a la admiración, hace que este eminente autor de la época sea reivindicado por el doctor Eximio. Así, en los Conimbricenses la referencia fisiológica se queda en la cita a Girolamo Fracastoro, toda vez que la risa queda reducida en su etiología a la alegría principalmente, sin por ello negarla, pues se menciona el hecho de la novedad previa. Aquí se amplía a la admiración, y es justamente en este tema donde se desarrolla la discusión entre Fracastoro y Valleriola. Y es que es, precisamente, en la ya mencionada obra sobre las Controversias en la que aparece (libro V, cap. 9) el tema que nos ocupa: De risu et fletu ${ }^{67}$. La diferencia entre Fracastoro y Valleriola, como señala Vallés, no estriba tanto en el mecanismo fisiológico, cuanto en su origen o etiología. Lo que hace Vallés en su Controversias (V, cap. IX) es preguntarse si la risa es natural a los hombres, si sus efectos fisiológicos, a saber la vibración del diafragma y los músculos del corazón, puede conducir al hombre a la muerte. Enuncia lo que Suárez va a presentar: si estos síntomas fisiológicos tienen relación con las pasiones o emociones del espíritu, de facto si intervienen, entonces de qué modo la alegría y la sorpresa (manifestado así en los Conimbricenses) o admiración (como aparece en Suárez) ${ }^{68}$ pueden darse en el mismo hecho. En fin, la pregunta que se está realizando es cómo una acción física que en cierta forma (que puede ser hasta violenta) influye en el hombre, es humana, y en ello, cuál es su vinculación a su constitución espiritual. La afirmación de Vallés supone, en fin, el hecho de humanizar de forma definitiva la risa, aquella que tradicionalmente se vinculó a la actividad pasional de la concupiscencia, en sus colorarios más apegados a lo negativo del cuerpo. Lo enunciado por algunos teólogos en una vinculación pasional, queda

\footnotetext{
66 Franciscus Vallesius, Controversiarum medicarum et philosophicarum libri decem (ex officina Ioannis Brocarii, Compluti 1556) (Ed. española por F. Calero, C.S.I.C., Madrid 1988). Sobre le médico de Covarrubias cf. J.L. Barona, Sobre medicina y filosofía natural en el Renacimiento, Universitat de Valencia, Valencia 1993, pp. 197-215; A.I. Martín, «Médicos y medicina en la Universidad de Alcalá», in Historia de la Universidad de Alcalá, Servicio de Publicaciones de la Universidad de Alcalá, Alcalá 2009, pp. 565-586.

67 Franciscus Vallesius, Controversiarum, V, c. 9 (trad. española pp. 314ss.).

68 Ibid., pp. 314-321.
} 
completada en un proceso más complejo de elaboración por parte del hombre. Vallés, adopta en la risa una visión monista del reír (en el reconocimiento de la alegría y la admiración) siguiendo la estela de Fracastoro.

Girolamo Fracastoro (1478-1553) es pionero y, por lo tanto, personaje central de lo que se conoce como Humanismo médico: "Dentro del humanismo médico -señala Enrique Montero hablando de Girolamo Fracastoro- ocupa una posición excepcional este gran humanista veronés, cuyo poema de corte virgiliano mereció la alabanza de hombres de la talla de Pierio Valeriano, Giovanni Battista Ramusio, Pietro Bembo o Julio César Escalígero, a pesar de encontrar imperfecciones de variado tipo" 69. Como más tarde con Vallés, nos encontramos frente a un hombre que destaca como médico y humanista y que le llevó a ser considerado un erudito en los círculos eclesiásticos. La fama nace de su obra y se refleja en la repercusión que tuvo la misma, por ejemplo el Syphilis Sive Morbus Gallicus (Sifilis o enfermedad francesa) escrito en 153070, o De Contagione et Contagiosis Morbis (Sobre el contagio y las enfermedades infecciosas) de 154671, y en los cargos que ocupó (llegó a ser el médico del Concilio de Trento y del papa Pablo III). La obra a la que hace referencia el texto de Suárez es el De sympathia et antipathia rerum, liber unus $(1546)^{72}$. Un texto de filosofía natural en el que afirma la conexión de todas las cosas en la naturaleza de forma que las cosas similares se atraen (simpatía) y las disímiles se repelen (antipatía). Fracastoro intenta realizar una explicación fenoménica de la realidad natural a partir de una visión «científica» que evite y rechace la apelación al recurso de lo "oculto", un intento que procuró en otras obras como la "filosófica" De anima (1553), un diálogo que trata la naturaleza psicológica a partir de sus experiencias como médico y sus reflexiones filosóficas ${ }^{73}$. En esta obra se analizan los fenómenos propios de la existencia del hombre y del alma en la vida desde las categorías de la física y psicología aristotélicas, para después recurrir a la teología con el fin de afirmar la existencia inmortal del alma, una inmortalidad que deviene de su participación en la armonía universal (como en la Simpatía). En el asunto de la risa Fracastoro entiende, como más tarde Vallés, que la risa no puede nacer de dos emociones contrarias. La risa nace de una combinación de la alegría (laetitia) y la admiración (admiratio). Hacer prevalecer en la risa dos efectos con-

69 E. Montero, Tipología de la literatura médica latina. Antigüedad, Edad Media, Renacimiento, FIDEM, Porto 2010, p. 160.

70 Hieronymus Fracastorus Veronensis, Syphilis siue morbus Gallicus (Veronae, 1530). Edición en L. Baumgartner y J.F. Fulton, A bibliography of the poem «Syphilis sive morbus gallicus» by G. F. of Verona, New Haven 1935

${ }^{71}$ Hieronymus Fracastorus Veronensis, De sympathia et antipathia rerum liber vnus. De contagione et contagiosis morbis et curatione libri III (apud haeredes Lucaeantonii Iuntae, Venetiis 1546).

72 Ibid.

73 Hieronymus Fracastorus Veronensis, Opera omnia (apud haeredes Lucaeantonii Iuntae, Venetiis $1555)$. 
trarios es un problema pues la alegría y la admiración producen efectos diversos en la dilatación del diafragma, mientras la primera tiende a dilatarlo, la segunda tiende a lo contrario. Este conflicto es, para el médico italiano, claramente de origen mental, lo que supone en cierta forma una lucha entre el cuerpo y el espíritu. Se hace presente aquí la influencia del platonismo revalorizado en la época y que subraya esta dualidad espiritual-corporal, de no pocas consecuencias en la modernidad. Fracastoro intenta restringir las consecuencias de ese dualismo platónico en el hecho de la risa reduciendo un elemento a otro.

Por su parte, el tercer protagonista del comentario de Suárez es el médico de Montpellier Franciscus Valleriola (François Valleriola, 1504-1580) quien se inscribe dentro del espíritu médico renacentista, de fuerte raigambre hipocrática. En su obra Ennarationes ${ }^{74}$ aborda la cuestión de la risa. Para el médico francés, la risa es el resultado de una suma de placer y admiración bajo el consentimiento del alma. En este sentido intenta realizar una superación del debate desde la dualidad humana, de modo que los elementos pueden combinarse. Y aquí aparece la tesis que tiene que ser negada, pues compromete la vinculación a la risa de una admiración de fuente espiritual, dejándose, así, abierta la puerta al dualismo.

La citación de estos autores, incluso más allá del tema de la risa y sus vinculaciones filosóficas, no hace sino reflejar una situación dentro los estudios filosóficos y médicos que estaban operando una transformación en la consideración de los elementos de las acciones humanas y psicológicas, así como la ampliación de las perspectivas meramente anímicas. En este sentido, se puede significar el hecho de que surjan estudios sobre la risa de marcado signo fisiológico vinculados a la psicología en relación en algunos casos con una variación de la designación que provoca que los estudios de anima se transformen en psicología, especialmente en este periodo que va del último cuarto del siglo XVI al primero del XVII. El área geográfica de extensión del término, y ello puede ser relevante en el paradigma difusor del modernismo, se circunscribe a los Países Bajos y Alemania, especialmente en torno a las universidades de Marburgo y Leyden ${ }^{75}$.

Un caso paradigmático es el de Rudolf Goclenius (Rudolf Göckel, 1547-1628), autor de un tratado sobre la risa y otro de psicología. Este autor publicó en 1607 la obra Physica commentatius de Risu et lacrymis ${ }^{76}$, una obra que se inscribe dentro de un proceso de renovación de los estudios sobre el hombre. El hecho de que Rudolf Goclenius utilizara el nombre de psicología no era por casualidad él fue pionero en su utilización pues fue quien por primera vez en el título de un tratado puso el nombre de "psicologia" (ЧҮХО ОГІА: hoc est, De hominis perfectione, animo

\footnotetext{
74 Franciscus Valleriola, Enarrationes medicinales, S. Gryphius, Lyons 1554.

75 Cf. P. Mengal, "La constitution de la psychologie comme domaine du savoir aux XVIème et XVIIème siècles”, Revue d'Histoire des Sciences Humaines, 1/n.2 (2000) 5-27.

76 Marpurgi 1597.
} 
et in primis ortu hujus, commentationes ac disputationes quorundam theologorum $\&$ philosophorum nostrae aetatis ${ }^{77}$ ). Este hecho no puede ser reducido a mera anécdota y sus resultados son una renovación de los de Vallés. Aquí tenemos el reflejo de una actitud del profesor de Marburgo que lo aproxima a las hermenéuticas antiescolásticas de las tesis aristotélicas (quaecumque ab Aristotele dicta essent commentitia esse) conocidas bajo el nombre de 'ramismo' nacidas de Petrus Ramus (Pierre de la Ramée, 1515-1572), un personaje como sabemos de gran influencia en el periodo humanista del siglo XVI -no por azar, por lo tanto, el filósofo y jurista Freigius (Johann Thomas Freig, 1543-1583), admirador de Ramus, presenta el primer testimonio escrito del término en una obra ${ }^{78}$. Sin duda alguna, se trata de una apuesta más por una lectura sobre el alma que adquiera una mirada diferente al abordaje aristotélico a partir del De anima y el De sensu et sensato. La estela de Petrus Ramus se deja ver en los ambientes parisinos y en humanistas de toda Europa -en España, por ejemplo en el pensamiento lógico-dialéctico de Francisco Sánchez de las Brozas (1523-1600) y el español Pedro Núñez Vela (1522-1602)-. La disputa que alcanzó también una significación política, en el sentido de los diferentes apoyos que se fueron estableciendo respecto de la figura del filósofo francés, no fue ajena a la reacción de los círculos intelectuales cristianos y a las órdenes religiosas. En este sentido, la Compañía de Jesús promovió la inclusión de sus obras en el Índex librorum prohibitorum. La mirada de Ramus y sus seguidores, en este caso en el tema de la psicología de Goclenius, no acapara todo el humanismo, no se trata de una dialéctica entre escolásticos y humanistas encerrados en dos grupos diferenciados, sino que manifiesta las diferentes interpretaciones que existían. De modo que se va estableciendo en el tiempo una evolución del humanismo, en la que Ramis, por ejemplo, se aleja del humanismo italiano (de hecho se denomina de forma propia a su pensamiento 'ramismo') 79 , y del mismo modo, el escolasticismo va abriéndose a nuevos caminos con el devenir del tiempo y la propia exigencia intelectual. En este sentido, el tratado de Rudolf Goclenius recoge opiniones diversas desde visiones críticas con el aristotelicismo dominante, autores más o menos conocidos como el caso de Nicolaus Taurellus (Nikolaus Öchslin, 1547-1606), más precisamente de su obra Philosophiae triumphus: "Nicolaus Taurellus philos. et Med. Doctor ac Prosessor in Academia Norica, in philosophia triumpo, pag. 28 et sequentibus" $"$. La utilización de la palabra psicología conoce un cierto efecto,

\footnotetext{
77 Pauli Egenolphi, Marpurgi 1590 (consultado Egenolphi, Marpurgi 1594).

78 Johannes Thomas Freigius, Ciceronianus Ioannis Thomae Freigii in quo: Ex Ciceronis Monumentis Ratio instituendi locos communes demonstrata \& eloquentia cum Philosophia coniuncta, descripta est libris decem, Sebastianum Henricpetri, Basileae 1575.

79 W.J. Ong, Ramus, Method, and the Decay of Dialogue: From the Art of Discourse to the Art of Reason, University of Chicago Press, Chicago 2004 (1 ed. 1958), p. 49.

80 Rodolfus Goclenius, $\psi 1 \chi 0$ ○o $\gamma 1 \alpha$ : hoc est (Marpurgi 1594, pp. 303-305). La obra a la que hace referencia es como ya hemos señalado: Nicolaus Taurellus, Philosophiae triumphus seu metaphysica philosophandi methodus, Sebastianum Henricpetri, Basilae 1573.
} 
incluso en otras áreas geográficas, lo que implica en el mundo no protestante, en autores como en el médico-filósofo y científico italiano Fortunio Liceti (Fortunius

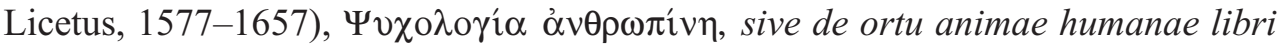
III $(1606)^{81}$, no por causalidad docente primero de filosofía y después de medicina de la Universidad de Padua, una universidad de gran importancia en la transformación de la ciencia médica.

En este ambiente de discusión científica, Rudolf Goclenius, el joven, publicó en 1607 la obra Physiologia crepitus ventris, et risus recognita explanata et Iterato ${ }^{82}$, una obra que se inscribe dentro de un proceso de renovación de los estudios acerca del hombre sobre la risa, donde se muestra en extenso, en sus análisis y discusiones, los problemas que son señalados en líneas en el tratado de Suárez. Así el autor adopta la explicación fisiológica (de la que él confiesa es especialista ${ }^{83}$ ) sobre el origen diafragmático de la risa y su relación al corazón. A continuación sigue la discusión en torno al origen del "cosquilleo" el fenómeno que se discutía con

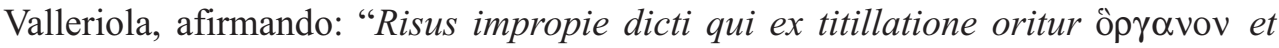
sedes est diaphragma" 84 y que todo caso la risa tiene una causa natural (no voluntaria) lo que en su opinión es más válido para poder explicar adecuadamente ciertos fenómenos que serán discutidos en la teología como el caso de si Jesús reía o no ${ }^{85}$. La obra es el reflejo de una serie de estudios sobre la risa ${ }^{86}$ en torno a la época del comentario suareciano, entre los que pueden mencionarse las obras de Antonii Larentini Politiani: De risu eiusque causis et effectibus libri duo (1603), en una obra de Nicander Jossius titulada Tractatus novus, utilis et iucundus de voluptate et dolore, de risu et fletu, somno et vigilia, deque fame et siti (1603), obra a la que está asociada el De risu et ridiculus de Mancinius (Celso Mancini, 1542-1612)87. No podemos olvidar en este conjunto de tratados sobre la risa, la obra de Laurent Joubert (1529-1582), canciller de la prestigiosa Facultad de Medicina de Montpellier88:

81 Francofurti 1606 (la primera edición, no editada en Alemanía, sin embargo aparece sin el nombre de psicología, De ortu animae..., Genuae 1602).

82 Officina Paltheniana, Francofurti 1607: De risu et ridiculo pp. 40-73.

83 Rodolfus Goclenius (el joven), Physiologia crepitus..., op. cit., p. 41

84 Ibid., pp. 43-44.

85 Ibid., probl. XI, p. 59.

86 Cf. D. Ménanger, La Renaissance et le rire, PUF, Paris 1995.

87 Nicandrus Iossius - Joannes Adolphus Kelnerus, Tractatus nouus, vtilis \& iucundus, de voluptate et dolore, de risu et fletu, somno et vigilia, deque fame \& siti ... Cui accesserunt Antonii Laurentii Politiani, De risu, eiusque causis et effectis, dilucide ac philo-sophice tractatis, libri duo. Antea nunquam editi, nunc vero in gratiam studiosorum in lucem emissi, Wolffgangi Richteri, sumptibus Ioannis Theobaldi Schönwetteri, Francofurti 1603 (Una edición anterior de la obra: Iossius Nicandrus, Opuscula de voluptate et dolore, de risu et fletu, de somno et vigilia, de fame et siti Nicandri Iossii, Zanettus, Romae 1580).

88 Cf. L. Dulieu, "Laurent Joubert, chancellier de Montpellier", Bibliothéque d'Humanisme et Renaissance, 31 (1969) 139-167. 
Traité du ris (1579) ${ }^{89}$. El autor francés trata la especificidad humana de la risa desde el intento de superación del dualismo platónico y en una tradición que va más allá de la fisiología aristotélica. Así, en la medida que el hombre posee un órgano que aparece como principal instrumento de la risa, esta especificidad anatómica le diferencia del resto de los animales que no precisan de ella al carecer de dicha facultad de reír. De esta forma, el conflicto entre cuerpo y alma queda matizado. Siguiendo, no obstante las actividades pasionales en una división tripartita del alma platónica, como lo hacen desde la escolástica en los comentarios al De anima que venimos señalando, vincula el carácter físiológico a la etiología de las mismas y de sus acciones, en este caso la risa. Y aún más cercano a Velleriola, en el fondo señala lo que subyace a esta cuestión y que sirve de elemento realmente refrescante en el devenir de la tradición de la Edad Media al Barroco pasando por el Renacimiento: si las acciones dependen el alma apetitiva, es decir del corazón o bien se centran en el aspecto fisiológico (donde Joubert inicia una reducción mecánica del hombre) o bien enunciamos una vinculación a lo psicológico en cuanto alma: e intentamos trascender el dualismo.

\section{La admiración}

Juan de la Torre y Valcárcel, conocido escolasticista, y galenicista, escribe en su Espejo de la philosophia y compendio de toda la medicina theorica y practica (libro 2, tratado 3, q. VII, n. 6: "Qué cosas sean las pasiones del alma y quáles") sobre la risa:

Quando es cosa agradable la que le causa de repente novedad à los sentidos del hombre, suele à este causarle risa, de la qual se sigue el gozo, y desde la dilectacion del coraçon hasta la boca del septo transverso, y diafragama. De las ocasiones ya declaradas de la admiracion inferiràs la razón del reìrse mucho los poco entendidos, y es, por que todo lo mas se les haze novedad. De donde dezimos comunmente, que la innorancia es causa de la risa, como lo advirtió Valles, 5. Controv. Cap 9 y tambien lo es del llanto excessivo, porque este nace de ignorar los remedios, y motivos del consuelo 90 .

Se tratan de unas palabras que se acercan mucho a las afirmaciones que daba Suárez y de las que hablamos con anterioridad y en la que aparece similar cita de Vallés. En fin, se trata de la doctrina común. El hecho de que el sacerdote y médico de Carlos II, quien estudió Artes, Teología y, posteriormente, Medicina en

89 Laurent Joubert, Traité du ris suivi d'un dialogue sur la Cacographie Française, Nicholas Chesneau, Paris 1579. F (trad. esp. Tratado de la risa, prólogo y notas de J. Mateo Ballorca y M. Jalón, Asociación Española de Neuropsiquiatría, Madrid 2002).

90 Utilizamos la edición de Juan Garcia Infançon, Madrid 1705, p. 177. 
Alcalá, describa en la segunda mitad del siglo XVII, una parecida reflexión nace, sin duda, de la circunstancia de que éste sigue, como el jesuita, las explicaciones de Vallés y de su formación filosófico-teológica. El autor, con anterioridad (nn. 11-12), hace referencia a la admiración retrotrayendo su forma como pasión a Avicena. La admiración nace de la novedad del objeto, pero puede causar diversas reacciones y clasificarse de diversos modos: arrebato del entendimiento (éxtasis), nacida de objeto temible (horrida admiratio) y "cosas de incógnita naturaleza que agradan y deleitan"; a este tercer tipo, que solo se da-como el primero- en los hombres, pertenece la risa. La risa en explicación galénica se vincula a la pasión sensitiva como actividad que surge de la admiración unida al deleite, a lo agradable.

La admiración es el gozne sobre el que se construye la derivación barroca de la risa. El Renacimiento veía el problema desde el punto de vista fisiológico en su vinculación con la teoría platónica del alma y dualista del hombre. Pero el Barroco empieza a vislumbrar que aquí se esconde una cuestión sobre la antropología subyacente, y la apuesta por el equilibrio o por los reduccionismos, por el objetivismo o por el subjetivismo. Así, la vinculación de la risa a la admiración es el signo evidente del cambio que los autores de esta época realizan y a las que Suárez se acoge. Pues la admiración implica una captación subjetiva de la acción que necesariamente lleva sujeta una actividad racional, aunque la sorpresa irrumpa en la razón de forma no silogística o "estrictamente" racional. Por lo tanto, advertir que la admiración es un elemento etiológico en el proceso de la risa, y hacerlo en un comentario aristotélico sobre el hombre, en una circunstancia en la que se subraya (más allá de lo que Aristóteles quería decir) que la risa es un elemento humano, implica llevar al campo de la Escolástica todo el nuevo bagaje médico-filosófico. Un hecho totalmente novedoso en el que la admiración queda unida a la racionalidad del hombre, de modo que como señala Daniel Ménanger: la risa se reconcilia con el hombre $^{91}$. La risa se reconcilia con la filosofía, con la razón. La pasión queda, a su vez, reconciliada con la razón, elevada del sitio en la que está siendo interpretada: la pasión concupiscible. El alma, y el cuerpo, también quedan revitalizados. Y aquí Suárez, en un increíble ejercicio de previsión de lo que se puede avecinar al incurrir en un pensamiento donde aparezcan como momentos separados los fenómenos racionales y la mecánica científica, sitúa la psiqué en un punto de fisiología donde el soma se hace imprescindible a su ejercicio, de la misma forma que la fisiología queda vinculada a la racionalidad.

La tradición medieval queda superada en sus consecuencias y la modernidad queda definida en la advertencia de las mismas. Suárez va adelantando así la necesidad de recurrir a una interpretación completa (antropológica) del ser humano, somatizando la psiqué y racionalizando la actividad fisiológica, es decir vinculán-

91 D. Ménanger, La Rennaisance..., op. cit., p. 226. 
dola. El salto que realizará Descartes está enunciado en sus consecuencias en la mirada realizada en el Comentario al De anima de Suárez (de un modo que el propio Aristóteles queda superado al revisar el contenido en el Comentario, en una forma propia nacida en el comentario renacentista que entendía a los lectores de Aristóteles como intérpretes ${ }^{92}$ ). Desarrolla, el doctor Eximio, toda una teoría de las pasiones en la revitalización de la psicología humana que ya aparecía en la medicina del humanismo renacentista, pero que también fue señalada en la literatura del siglo XV filosófico-teológica. Cuando Alfonso Martínez de Toledo, arcipreste de Talavera de la Reina (1398-1468), escribe El Corbacho o Reprobación del amor mundano o Arcipreste de Talavera y hace referencia a las conexiones entre la astrología y la medicina, en especial en la teoría de los cuatro humores: colérico, melancólico, sanguíneo y flemático, señala que el sanguíneo - cuyas características eran las de ser valiente, esperanzado, amoroso- es para el arcipreste talaverano el tipo de hombre cuyo carácter es propenso a la risa93. La risa aparece así como objeto de análisis psicológico (junto a los aspectos literarios y espirituales). Se entienden aquí las palabras del profesor José Luis Fuertes cuando revisando la novedad de la pedagogía y el currículo jesuita señala la dificultad de encontrar "el difícil equilibrio que se imponía a la propia Compañía entre lo institucional, aristotélico-tomista, y el espíritu de búsqueda en la libertad que la premura del tiempo estaban exigiendo". Realidades que depararían más de una discusión y que tiene en nuestro autor la decisión de "no seguir estrechamente a Santo Tomás" 94. En su elección y la forma de la misma se refleja su lucidez y novedad. Suárez recoge toda la tradición sumada y la va reelaborando para preparar una modernidad. Preparar no significa realizar, sino señalar, delimitar, indicar, y advertir, ad intra y ad extra las consecuencias del pensar.

\section{Manuel Lázaro Pulido \\ Gabinete de Filosofia Medieval \\ Universidade do Porto}

\footnotetext{
92 Cf. L. Bianchi, Studi sull'aristotelismo del Rinascimento, Il Poligrafo, Padova 2003, p. 193.

93 "Estos tales son onbres muy alegres, plazenteros e muchos rientes de voluntad. De una paxarrilla que vaya bolando [se reyrán] fasta saltárseles las lágrimas de los ojos.. Non tyenen gesto ni risa ynfingida..." (Alfonso Martínez de Toledo, Arzipreste de Talavera o Corbacho, III., cap. VII, ed. de J. González Muela, Castalia, Madrid 19070, p. 190, citado en F. López, "La poética de la risa”, op. cit., p. 13).

94 J.L. Fuertes, "La escolástica del Barroco: presencia del Cursus Conimbricensis en el Pharus Scientiarum (1659) de Sebastián Izquierdo", en M.C. Pacheco - J.F. Meirinhos (ed.), Intellect et imagination dans la philosophie médiévale / Intellect and Imagination in Medieval Philosophy / Intelecto e imaginação na Filosofia Medieval. Actes du XIe Congrès International de Philosophie Médiévale de la Société Internationale pour l'Étude de la Philosophie Médiévale (S.I.E.P.M.). Porto, du 26 au 31 août 2002, vol. 1, Brepols, Louvain la Neuve 2006, p. 163.
} 